\title{
Technical Note: New ground-based FTIR measurements at Ile de La Réunion: observations, error analysis, and comparisons with independent data
}

\author{
C. Senten ${ }^{1}$, M. De Mazière ${ }^{1}$, B. Dils ${ }^{1}$, C. Hermans ${ }^{1}$, M. Kruglanski ${ }^{1}$, E. Neefs ${ }^{1}$, F. Scolas ${ }^{1}$, A. C. Vandaele $^{1}$, \\ G. Vanhaelewyn ${ }^{1}$, C. Vigouroux ${ }^{1}$, M. Carleer ${ }^{2}$, P. F. Coheur ${ }^{2}$, S. Fally ${ }^{2}$, B. Barret ${ }^{3,}{ }^{*}$, J. L. Baray ${ }^{4}$, R. Delmas ${ }^{4}$, J. \\ Leveau $^{4}$, J. M. Metzger ${ }^{4}$, E. Mahieu ${ }^{5}$, C. Boone ${ }^{6}$, K. A. Walker ${ }^{6,7}$, P. F. Bernath ${ }^{6,8}$, and K. Strong ${ }^{7}$ \\ ${ }^{1}$ Belgian Institute for Space Aeronomy (BIRA-IASB), Brussels, Belgium \\ ${ }^{2}$ Service de Chimie Quantique et Photophysique (SCQP), Université Libre de Bruxelles (ULB), Brussels, Belgium \\ ${ }^{3}$ formerly at: BIRA-IASB and SCQP/ULB \\ ${ }^{4}$ Laboratoire de l'Atmosphère et des Cyclones (LACy), Université de La Réunion, France \\ ${ }^{5}$ Institute of Astrophysics and Geophysics, University of Liège, Liège, Belgium \\ ${ }^{6}$ Department of Chemistry, University of Waterloo, Waterloo, Ontario, Canada \\ ${ }^{7}$ Department of Physics, University of Toronto, Toronto, Ontario, Canada \\ ${ }^{8}$ Department of Chemistry, University of York, Heslington, York, UK \\ *now at: Institut d'Aérologie, Toulouse, France
}

Received: 1 November 2007 - Published in Atmos. Chem. Phys. Discuss.: 17 January 2008

Revised: 23 April 2008 - Accepted: 20 May 2008 - Published: 2 July 2008

\begin{abstract}
Ground-based high spectral resolution Fouriertransform infrared (FTIR) solar absorption spectroscopy is a powerful remote sensing technique to obtain information on the total column abundances and on the vertical distribution of various constituents in the atmosphere. This work presents results from two FTIR measurement campaigns in 2002 and 2004, held at Ile de La Réunion $\left(21^{\circ} \mathrm{S}, 55^{\circ} \mathrm{E}\right)$. These campaigns represent the first FTIR observations carried out at a southern (sub)tropical site. They serve the initiation of regular, long-term FTIR monitoring at this site in the near future. To demonstrate the capabilities of the FTIR measurements at this location for tropospheric and stratospheric monitoring, a detailed report is given on the retrieval strategy, information content and corresponding full error budget evaluation for ozone $\left(\mathrm{O}_{3}\right)$, methane $\left(\mathrm{CH}_{4}\right)$, nitrous oxide $\left(\mathrm{N}_{2} \mathrm{O}\right)$, carbon monoxide $(\mathrm{CO})$, ethane $\left(\mathrm{C}_{2} \mathrm{H}_{6}\right)$, hydrogen chloride $(\mathrm{HCl})$, hydrogen fluoride $(\mathrm{HF})$ and nitric acid $\left(\mathrm{HNO}_{3}\right)$ total and partial column retrievals. Moreover, we have made a thorough comparison of the capabilities at sea level altitude (St.-Denis) and at $2200 \mathrm{~m}$ a.s.l. (Maïdo). It is proved that the performances of the technique are such that the atmospheric variability can be observed, at both locations and in distinct
\end{abstract}

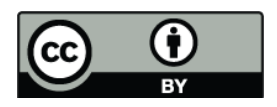

Correspondence to: C. Senten (cindy.senten@aeronomie.be) altitude layers. Comparisons with literature and with correlative data from ozone sonde and satellite (i.e., ACE-FTS, HALOE and MOPITT) measurements are given to confirm the results. Despite the short time series available at present, we have been able to detect the seasonal variation of $\mathrm{CO}$ in the biomass burning season, as well as the impact of particular biomass burning events in Africa and Madagascar on the atmospheric composition above Ile de La Réunion. We also show that differential measurements between St.-Denis and Maïdo provide useful information about the concentrations in the boundary layer.

\section{Introduction}

The Network for the Detection of Atmospheric Composition Change ${ }^{1}$ (NDACC, http://www.ndacc.org/) is a worldwide network of observatories, for which primary objectives are to monitor the evolution of the atmospheric composition and structure, and to provide independent data for the validation of numerical models of the atmosphere and of satellite data. NDACC also supports field campaigns focusing on specific processes at various latitudes and seasons. Only

\footnotetext{
${ }^{1}$ This was formerly called the Network for the Detection of Stratospheric Change or NDSC.
}

Published by Copernicus Publications on behalf of the European Geosciences Union. 
a few stations in NDACC are situated in the tropical and subtropical belts. In particular, there are not yet any longterm Fourier transform infrared (FTIR) measurements in the Southern Hemisphere tropics. The only tropical NDACC stations at which FTIR measurements are performed are Mauna Loa $\left(19.54^{\circ} \mathrm{N}, 155.6^{\circ} \mathrm{W}\right)$ and Paramaribo $\left(5.8^{\circ} \mathrm{N}\right.$, $55.2^{\circ} \mathrm{W}$ ), both in the Northern Hemisphere. The former one is at high altitude ( $3459 \mathrm{~m}$ a.s.l.), and at the latter one, the measurements are performed on a campaign basis, since September 2004 only (Petersen et al., 2008). Therefore, we have chosen the Observatoire de Physique de l'Atmosphère de La Réunion (OPAR) to initiate such measurements. The OPAR is located at $21^{\circ} \mathrm{S}, 55^{\circ} \mathrm{E}$, in the Indian Ocean, East of Madagascar, at the edge between the southern tropics and subtropics. It is a measurement station led by the Laboratoire de l'Atmosphère et des Cyclones (LACy) of the Université de La Réunion, that performs radio sonde observations since 1992, SAOZ measurements since 1993 and lidar measurements since 1994 (Baray et al., 2006). The implementation of FTIR solar absorption measurements at this site, providing information about the total column abundances and vertical distributions of a large number of atmospheric constituents (e.g., Brown et al., 1992), will therefore be a useful complement to the station's observations, and will fill the gap in the Southern Hemisphere tropical region.

In this paper, we present results from the first two FTIR campaigns that we performed at Ile de La Réunion, in 2002 and 2004, to verify the feasibility of FTIR measurements at a tropical site and to start the long-term monitoring. Knowing that water vapour is a strong absorber in the infrared and that there is a larger humidity at tropical sites than at midand high-latitude sites, especially at low altitude, it is important to characterize the capabilities of FTIR monitoring at a tropical location. During the first campaign we have made simultaneous measurements at two locations with an altitude difference of about $2.2 \mathrm{~km}$, to compare the observation characteristics at these two altitudes. This campaign has also allowed us to make some differential measurements, characterizing the boundary layer. The second campaign was made at the lowest altitude site, to initiate the long-term measurements and to contribute to satellite validation, in particular of the Atmospheric Chemistry Experiment - Fourier Transform Spectrometer (ACE-FTS), onboard the Canadian satellite SCISAT-1 (http://www.ace.uwaterloo.ca).

The results presented here concern a number of species that have been selected for three main reasons: their important roles in tropospheric or stratospheric chemistry, their link to current environmental problems like climate change or stratospheric ozone depletion, and the fact that they are needed for satellite validation. More specifically, our analyses focus on the primary greenhouse gases $\mathrm{CH}_{4}, \mathrm{~N}_{2} \mathrm{O}$ and $\mathrm{O}_{3}$, on the secondary greenhouse gases $\mathrm{CO}$ and $\mathrm{C}_{2} \mathrm{H}_{6}$, and on $\mathrm{HCl}, \mathrm{HF}$ and $\mathrm{HNO}_{3}$. Apart from their indirect effect on climate change, $\mathrm{CO}$ and $\mathrm{C}_{2} \mathrm{H}_{6}$ play a central role in tropospheric chemistry through their reactions with the hydroxyl radical OH (Brasseur and Solomon, 1984). They are emitted primarily by anthropogenic sources, and they can be used as tracers of tropospheric pollution and transport (e.g., transport of emissions from biomass burning), because they have relatively high tropospheric abundances and long tropospheric lifetimes.

In the stratosphere, $\mathrm{HCl}$ has a non-negligible impact on the ozone budget, acting as a reservoir species for chlorine. HF is a useful tracer of vertical transport, and of the anthropogenic emissions of fluorinated compounds.

$\mathrm{HNO}_{3}$ is formed in the reaction of $\mathrm{OH}$ with $\mathrm{NO}_{2}$ and plays an essential role as a reservoir molecule for both the $\mathrm{NO}_{\mathrm{x}}$ (nitrogen oxides) and $\mathrm{HO}_{\mathrm{x}}$ (hydrogen oxides) radicals, which are potentially active contributors to the ozone destruction in the stratosphere through catalytic reactions.

The results cover only short time periods, but their comparison with literature data and with correlative measurements shown in the paper, demonstrate the potential of these measurements at Ile de La Réunion. In particular, we show that the location of the site East of Africa and Madagascar offers interesting opportunities to observe transport of biomass burning emissions.

Sections 2, 3 and 4 describe the campaign characteristics, the retrieval method and the optimal retrieval parameters for every selected molecule individually. Section 5 presents the associated error budget calculations, together with a discussion of the resulting error estimations. Section 6 discusses the FTIR data as well as comparisons with correlative data. Conclusions and future plans are given in Sect. 7.

\section{Specifications of the FTIR measurement campaigns}

During the first FTIR solar absorption measurement campaign at Ile de La Réunion, in October 2002, two almost identical instruments, i.e., mobile Bruker 120M Fourier transform spectrometers, were operated in parallel at two different locations. The one belonging to the Belgian Institute for Space Aeronomy (BIRA-IASB) was installed on the summit of the mount Maïdo (2203 m a.s.1., 21 ${ }^{\circ} 04^{\prime} \mathrm{S}$ and $55^{\circ} 23^{\prime} \mathrm{E}$ ), and the one from the Universite Libre de Bruxelles (ULB) at the nearby St.-Denis University campus (50 $\mathrm{m}$ a.s.l., $20^{\circ} 54^{\prime} \mathrm{S}$ and $55^{\circ} 29^{\prime} \mathrm{E}$ ).

The BIRA-IASB instrument was placed in an airconditioned container, and the electricity was provided with a power generator located south of the container. The solar tracker (purchased from Bruker) was mounted on a mast attached to the wall of the container, and the solar beam entered the container through a hole in that wall. The ULB instrument was installed in a laboratory of the university. Its solar tracker (also purchased from Bruker) was attached to the edge of the roof of the laboratory and the solar beam entered the room through a side-window.

During the second campaign, from August to October 2004, we limited ourselves to one instrument from 
BIRA-IASB at St.-Denis only. The instrument was installed in the same container as in 2002, now put on the roof of a university building, with electricity provided by the university network. A different solar tracker was used, built at the University of Denver and modified at BIRA-IASB (Hawat et al., 2003; Neefs et al., 2007). In 2002 as well as in 2004, a second mast was used to carry a small meteorological station that belongs to the BARCOS system. BARCOS is the Bruker Automation and Remote COntrol System developed at BIRA-IASB to operate the FTIR experiment in an automatic or remotely controlled way (Neefs et al., 2007). It has successfully been used during both campaigns with the BIRA-IASB instrument. The BARCOS system includes a meteorological station and a data logger to continuously monitor and log the local weather conditions as well as other housekeeping parameters, i.e., instrument and environment status. BARCOS executes a daily script that schedules and runs the measurements. It interrupts the observation schedule when the solar tracker is not capable of tracking the sun because of the presence of clouds, and it resumes the schedule once the sun re-appears. BARCOS automatically closes or opens the suntracker hatch when it starts or stops raining, respectively. Unfortunately, at the time of the campaigns, the automatic filling of the detector dewars with liquid nitrogen was not implemented yet, and hence it was not possible to operate the FTIR instrument without a person on site.

Both spectrometers allowed a maximum optical path difference (MOPD) of $250 \mathrm{~cm}$, providing a maximum spectral resolution, defined as $0.9 / \mathrm{MOPD}$, of $0.0036 \mathrm{~cm}^{-1}$. Nevertheless, to record the solar absorption FTIR spectra, we have not always used the maximum spectral resolution. The actual resolution has been selected on the basis of the Doppler broadening of the lines and it has been lowered at high solar zenith angles, in order to reduce the measurement time. More specific information is given in Sect. 4. For all spectra, we have used a $\mathrm{KBr}$ beamsplitter in the interferometer, and one of six different optical bandpass filters in front of the detector, which is a nitrogen-cooled InSb (indium antimonide) or MCT (mercury cadmium telluride or $\mathrm{HgCdTe}$ ) detector, according to the target spectral range. The optical filters are the ones used generally in the NDACC FTIR community. In particular, during the first campaign in 2002 we have used filters 1, 2, 3, 5 and 6 , while during the second campaign in 2004 we have used filters 1, 2, 3, 4 and 6. So during the 2002 campaign the spectral region between 1400 and $2400 \mathrm{~cm}^{-1}$ has been covered using the MCT detector with the NDSC5 filter (range $1350-2250 \mathrm{~cm}^{-1}$ ). To improve the signal-tonoise ratio (SNR) in this spectral domain, during the 2004 campaign this region has been recorded with the InSb detector and the NDSC-4 filter (range $1850-2750 \mathrm{~cm}^{-1}$ ). This change in measurement configuration has an impact on the quality of the CO data, as will be seen in Sect. 5.2.

The total spectral domain thus covered by our measurements spans the wavenumber range from 600 to $4300 \mathrm{~cm}^{-1}$, in which it is possible to detect, among many other gases,

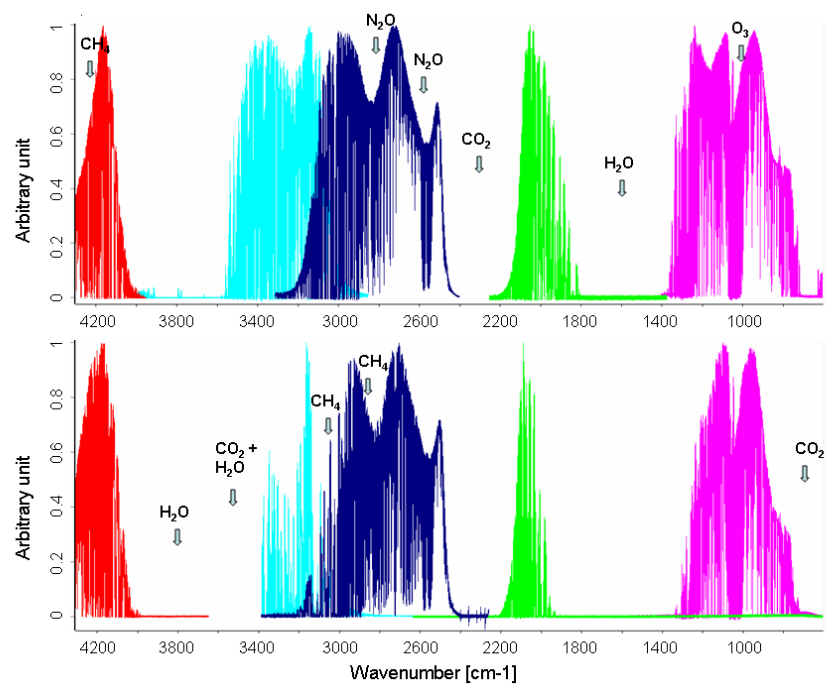

Fig. 1. Composite spectra for different bandpass filters (NDSC1: red, NDSC-2: blue, NDSC-3: dark blue, NDSC-5: green, and NDSC-6: pink), taken at Maïdo (upper plot) and at St.-Denis (bottom plot) in 2002, for solar zenith angles between 40 and $50^{\circ}$.

the target species $\mathrm{O}_{3}, \mathrm{CH}_{4}, \mathrm{~N}_{2} \mathrm{O}, \mathrm{CO}, \mathrm{C}_{2} \mathrm{H}_{6}, \mathrm{HCl}, \mathrm{HF}$ and $\mathrm{HNO}_{3}$. Figure 1 shows composite spectra from the first campaign in 2002, at Maïdo and at St.-Denis, including the different optical bandpasses (shown in different colours). For this figure, we selected spectra that were recorded on corresponding days for both locations and at solar zenith angles between 40 and $50^{\circ}$. All spectra have been standardized to improve the visibility of the figure. Note that some of the main absorbers are marked. One clearly observes the reduced absorptions by water vapour at the high-altitude site Maïdo. For example, the spectral range between 3000 and $3550 \mathrm{~cm}^{-1}$, that is completely opaque at St.-Denis, can be exploited at Maïdo.

Whenever the sky was clear at local noon, a reference $\mathrm{HBr}$ cell spectrum was recorded using the NDSC-4 filter. For this purpose, a cell containing hydrogen bromide $(\mathrm{HBr})$ at low pressure ( $2 \mathrm{mbar}$ ) was placed in the interferometer output beam in front of the InSb detector, and a spectrum was recorded using the sun as light source. When this was not possible on several consecutive days because of the noontime weather situation, the reference $\mathrm{HBr}$ cell spectrum was taken the same way, but using a tungsten lamp source. The cell spectra have been analysed using Linefit version 8 (Hase et al., 1999), to monitor the alignment of the instrument. For the ULB instrument at St.-Denis, a cell spectrum was taken only once during the first campaign; it confirmed the correct alignment of the instrument.

Because reliable solar absorption measurements require clear sky conditions, the number of observation days was limited: in total, we had about 24 days with observations during the first campaign and about 60 days during the second 
campaign. Also, during the first campaign, it was often not possible to perform the measurements simultaneously at both sites, because the local weather conditions were not necessarily the same. It is worth mentioning that most of the measurements have been carried out before noon, because most often clouds appeared in the afternoon. Sometimes additional late evening measurements have been possible at Maïdo.

\section{General description of the retrieval method}

As already mentioned, we have focused on the retrieval of ozone $\left(\mathrm{O}_{3}\right)$, methane $\left(\mathrm{CH}_{4}\right)$, nitrous oxide $\left(\mathrm{N}_{2} \mathrm{O}\right)$, carbon monoxide $(\mathrm{CO})$, ethane $\left(\mathrm{C}_{2} \mathrm{H}_{6}\right)$, hydrogen chloride $(\mathrm{HCl})$, hydrogen fluoride $(\mathrm{HF})$ and nitric acid $\left(\mathrm{HNO}_{3}\right)$. In addition to the total column abundances of these molecules, we have extracted information - whenever feasible - about their vertical distribution in the altitude range where the pressure broadening of the absorption lines can be resolved.

For these retrievals, we have used the inversion algorithm SFIT2 (v3.92), jointly developed at the NASA Langley Research Center, the National Center for Atmospheric Research (NCAR) and the National Institute of Water and Atmosphere Research (NIWA) at Lauder, New Zealand (Rinsland et al., 1998). This algorithm uses a semi-empirical implementation of the Optimal Estimation Method (OEM) of Rodgers (2000). Further details on the SFIT2 program can be found in the paper by Hase et al. (2004).

All retrievals are executed on a 44 layer altitude grid, starting at $50 \mathrm{~m}$ a.s.l. for St.-Denis and at $2200 \mathrm{~m}$ a.s.l. for Maïdo, with layer thicknesses of about $1.2 \mathrm{~km}$ in the troposphere and lower stratosphere up to $33.4 \mathrm{~km}$ altitude, then growing steadily to about $4 \mathrm{~km}$ around $50 \mathrm{~km}$ altitude and to about $8 \mathrm{~km}$ for the higher atmospheric layers up to $100 \mathrm{~km}$. This choice was made to take into account the local atmospheric pressure and temperature variabilities. Daily pressure and temperature profiles were taken from the National Centre for Environmental Prediction (NCEP).

For the error analysis (see Sect. 5.1.4) we also used temperature profiles from the European Center for Medium range Weather Forecasting (ECMWF).

\subsection{Forward model parameters}

The forward model in SFIT2 is a multi-layer multi-species line-by-line radiative transfer model. The instrument parameters in the forward model include a wavenumber scale multiplier and background curve parameters, as well as the actual optical path difference (OPD) and field of view (FOV) of the instrument. The background slope and curvature are determined by fitting a polynomial of degree 2 , and the wavelength shift is also fitted in every spectral micro-window independently.
To account for deviations from the ideal instrument line shape function (ILS) due to small instrument misalignments or imperfections, apodization and phase error functions are included. These functions can either be acquired from the Linefit analyses of the measured $\mathrm{HBr}$ cell spectra, or they can be approximated by a polynomial or a Fourier series of a user specified order. Our retrievals have been carried out using the second approach, i.e., fitted empirical apodization and phase error functions, because in all our retrievals this approach resulted in the smallest spectral residuals and the least oscillations in the retrieved profiles. In particular, we approximated the empirical apodization by a polynomial of degree 2 and, if beneficial, the empirical phase error by a polynomial of degree 1 .

\subsection{Inverse model}

The inverse problem consists of determining the state of the atmosphere, in particular the vertical distributions of the target molecules, from the observed absorption spectra. In order to solve this ill-posed problem, the SFIT2 retrievals request ad hoc covariance matrices for the uncertainties associated with the a priori vertical profiles of the target gases and with the measurements. The retrieved profiles and total column amounts of the target species are the ones that provide the best representation of the truth, given the measurements and the a priori information, and their respective uncertainties.

\subsubsection{A priori profile and associated covariance matrix}

The used a priori profile $\mathbf{x}_{a}$ and its covariance matrix $\mathbf{S}_{a}$ should well represent a first guess of the 'true' state, in order to reasonably constrain the retrieval solution, in particular at those altitudes where one can hardly get information out of the measurements. For each target gas we have decided to use one single a priori profile and associated covariance matrix for both campaigns, to avoid any biases between the results and to make sure that the results are directly comparable. The diagonal and off-diagonal elements of each $\mathbf{S}_{a}$ have been chosen such as to yield the best compromise between the spectral residuals, the number of oscillations in the retrieved profiles, and the number of degrees of freedom for signal (DOFS; see Sect. 3.3). We have assumed that the correlations between the layers decay according to a Gaussianshaped function. Details about the choice of the a priori vertical profiles and the associated covariance matrices are provided for each molecule individually in Sect. 4.2.

While we used constant values on the diagonal of $\mathbf{S}_{a}$ for the retrievals of all molecules, except $\mathrm{CH}_{4}$, we used more realistic uncertainties in the error calculations. Nevertheless, the $\mathbf{S}_{a}$ matrices used in the error analysis still have a Gaussian shape because of the limited knowledge about their full structure. 


\subsubsection{Measurement noise covariance matrix}

The retrieval covariance matrix associated with the measurements, $\mathbf{S}_{\varepsilon}$, is considered to be diagonal, containing an ad hoc estimation of the squared reciprocals of the SNR of the observed spectra as diagonal elements.

Together with the a priori covariance matrix of the profiles, the measurement noise covariance matrix has a great influence on the retrieval characterization and error analysis.

\subsubsection{Selection of spectral micro-windows}

Deriving information about the vertical distribution of trace gases out of high resolution FTIR spectra is possible because of the pressure broadening of the absorption lines, leading to an altitude dependence of the line shapes. While the line centers provide information about the higher altitudes of the distribution, the wings of a line provide information about the lower altitudes. Therefore the information content of the retrieval will strongly depend on the choice of the absorption lines. For all species, the absorption line parameters were taken from the HITRAN 2004 spectral database (Rothman et al., 2005). In addition, updates for $\mathrm{H}_{2} \mathrm{O}, \mathrm{N}_{2} \mathrm{O}, \mathrm{HNO}_{3}$ and $\mathrm{C}_{2} \mathrm{H}_{6}$ line parameters that are available on the HITRAN site (http://www.hitran.com) have been included. We have verified that they give similar or slightly better spectral fits than the original HITRAN 2004 values.

The retrieval spectral micro-windows are selected such that they contain unsaturated well-isolated absorption features of the target species with a minimal number of interfering absorption lines. One also aims at maximizing the amount of information present in the spectra, represented by the DOFS.

For the present retrievals, we adopted spectral microwindows used by other FTIR research groups and we verified slight modifications of those micro-windows, in order to improve our retrievals.

Further details about the micro-window selections and characteristics are discussed in Sect. 4.1.

\subsection{Information content and sensitivity}

The retrieved state vector $\mathbf{x}_{r}$ is related to the a priori and the true state vectors $\mathbf{x}_{a}$ and $\mathbf{x}$, respectively, by the equation

$\mathbf{x}_{r}=\mathbf{x}_{a}+\mathbf{A}\left(\mathbf{x}-\mathbf{x}_{a}\right)$

(Rodgers, 2000).

The rows of the matrix $\mathbf{A}$ are called the averaging kernels and the trace of $\mathbf{A}$ equals the DOFS. For each of the 44 layers the full width at half maximum of the averaging kernels provides an estimate of the vertical resolution of the profile retrieval at the corresponding altitude, while the area of the averaging kernel represents the sensitivity of the retrieval at the corresponding altitude to the true state. The DOFS together with the averaging kernel shapes will define the par- tial columns that best represent the retrieval results. The error analysis (Sect. 5) has been carried out for these partial columns.

\section{Retrieval strategy and spectral fits}

In this section, we give an overview of our retrieval approach for all target molecules.

Table 1 gives a summary of the selected retrieval microwindows (fitted simultaneously), the spectral resolution, the effective SNR, and the associated interfering molecules, together with our choice of the diagonal elements and the halfwidths at half-maximum (HWHM) defining the Gaussian inter-layer correlation length of $\mathbf{S}_{a}$ adopted in the retrieval, and finally also the achieved mean DOFS for each target species, at Maïdo in 2002, and at St.-Denis in 2002 and 2004.

\subsection{Spectral micro-window selections}

The micro-windows in which $\mathrm{O}_{3}, \mathrm{CH}_{4}, \mathrm{~N}_{2} \mathrm{O}, \mathrm{CO}$ and $\mathrm{C}_{2} \mathrm{H}_{6}$ are retrieved, as well as the interfering absorbers whose total columns are fitted simultaneously with the target species, have been adopted from the EC project UFTIR (http://www. nilu.no/uftir; De Mazière et al., 2004). Our tests have shown that these windows are still appropriate for the Maïdo and St.-Denis sites at Ile de La Réunion, despite the prevailing high humidity.

The UFTIR project also provided us with corrected spectral line parameters for ozone in the $2960-2980 \mathrm{~cm}^{-1}$ region (D. Mondelain and A. Barbe, private communication), which improve the spectral fits for $\mathrm{C}_{2} \mathrm{H}_{6}$. For $\mathrm{HF}$ and $\mathrm{HCl}$ the fitted micro-windows and interfering species were adopted from Reisinger et al. (1994) and from Rinsland et al. (2003), respectively. For the $\mathrm{HCl}$ retrievals, Rinsland et al. (2003) propose to fit two other micro-windows around 2727.78 and $2775.78 \mathrm{~cm}^{-1}$, in addition to the two windows we use. But since they contain strong interfering water vapour lines, fitting them appeared to be problematic at our (sub)tropical site. We therefore restricted our spectral fits to the two microwindows defined in Table 1 . The $\mathrm{HNO}_{3}$ micro-window selection is based on the discussions by Flaud et al. (2006) and Perrin et al. (2004).

4.2 Construction of a priori information and retrieval results

\subsubsection{Ozone $\left(\mathrm{O}_{3}\right)$}

For the $\mathrm{O}_{3}$ retrievals, we adopted a single mean a priori profile from the UGAMP (UK Universities Global Atmospheric Modelling Programme, http://ugamp. nerc.ac.uk/) climatology, calculated for a square of $2.5^{\circ} \times 2.5^{\circ}$ enclosing St.-Denis (http://badc.nerc.ac.uk/data/ ugamp-o3-climatology/), which provides a global 4-D 
Table 1. Summary of the retrieval characteristics for each target species, for the FTIR campaigns at Ile de La Réunion. Variab. represents the diagonal elements of $\mathbf{S}_{a}$ and HWHM the inter-layer correlation length in $\mathbf{S}_{a}$ The fourth, fifth and seventh columns list the spectral microwindows that are fitted simultaneously, the associated spectral resolution, and the main interfering species. SNR is the ad hoc signal-to-noise ratio adopted in the retrievals. The last column provides the mean DOFS achieved at Maïdo, 2002, and at St.-Denis, 2002 and 2004.

\begin{tabular}{|c|c|c|c|c|c|c|c|}
\hline Molecule & Variab. [\%] & $\begin{array}{l}\text { HWHM } \\
{[\mathrm{km}]}\end{array}$ & $\begin{array}{l}\text { Micro-window(s) } \\
{\left[\mathrm{cm}^{-1}\right]}\end{array}$ & $\begin{array}{l}\text { Spectral resolution } \\
{\left[\mathrm{cm}^{-1}\right]}\end{array}$ & SNR & $\begin{array}{l}\text { Interfering } \\
\text { species }\end{array}$ & $\begin{array}{l}\text { DOFS Maïdo / } \\
\text { St.-Denis }\end{array}$ \\
\hline $\mathbf{O}_{3}$ & 20 & 6 & $1000.00-1005.00$ & 0.0072 & 150 & $\mathrm{H}_{2} \mathrm{O}$ & $4.9 / 5.1$ \\
\hline $\mathbf{C H}_{4}$ & variable & 5 & $\begin{array}{l}2613.70-2615.40 \\
2650.60-2651.30 \\
2835.50-2835.80 \\
2903.60-2904.03 \\
2921.00-2921.60\end{array}$ & 0.00513 & 250 & $\begin{array}{l}\mathrm{HDO}, \mathrm{H}_{2} \mathrm{O} \\
\text { (fitted first), } \\
\mathrm{CO}_{2}\end{array}$ & $2.2 / 2.4$ \\
\hline $\mathbf{N}_{2} \mathbf{O}$ & 10 & 5 & $\begin{array}{l}2481.30-2482.60 \\
2526.40-2528.20 \\
2537.85-2538.80 \\
2540.10-2540.70\end{array}$ & 0.00513 & 150 & $\begin{array}{l}\mathrm{CO}_{2}, \mathrm{CH}_{4}, \mathrm{O}_{3}, \\
\mathrm{H}_{2} \mathrm{O}, \mathrm{HDO}\end{array}$ & $3.0 / 3.2$ \\
\hline CO & 20 & 4 & $\begin{array}{l}2057.70-2057.91 \\
2069.55-2069.72 \\
2157.40-2159.35\end{array}$ & 0.0036 & 150 & $\begin{array}{l}\mathrm{O}_{3}, \mathrm{OCS}, \mathrm{CO}_{2}, \\
\mathrm{~N}_{2} \mathrm{O}, \mathrm{H}_{2} \mathrm{O} \\
\text { solar CO lines }\end{array}$ & $2.6 / 2.8$ \\
\hline $\mathbf{C}_{2} \mathbf{H}_{6}$ & 40 & 5 & 2976.50-2977.20 & 0.00513 & 250 & $\mathrm{H}_{2} \mathrm{O}, \mathrm{CH}_{4}, \mathrm{O}_{3}$ & $1.5 / 1.7$ \\
\hline $\mathrm{HCl}$ & 20 & 5 & $\begin{array}{l}2843.30-2843.80 \\
2925.70-2926.60\end{array}$ & 0.00513 & 150 & $\mathrm{H}_{2} \mathrm{O}, \mathrm{CH}_{4}, \mathrm{HDO}$ & $1.2 / 1.4$ \\
\hline HF & 20 & 3 & $4038.70-4039.05$ & 0.0072 & 300 & $\mathrm{H}_{2} \mathrm{O}$ & $1.4 / 1.5$ \\
\hline $\mathrm{HNO}_{3}$ & 20 & 5 & $872.25-874.80$ & 0.01098 & 200 & OCS, $\mathrm{C}_{2} \mathrm{H}_{6}, \mathrm{H}_{2} \mathrm{O}$ & $1.0 / 1.2$ \\
\hline
\end{tabular}

climatological distribution of ozone covering the years 1985 to 1989 and the altitude range 0 to $100 \mathrm{~km}$.

Figure 2 shows the single micro-window fit of $\mathrm{O}_{3}$ from a single spectrum on 13 October 2002 and 15 October 2004 at Maïdo and St.-Denis, respectively, together with the residuals, computed as measured minus simulated transmission. In the spectral fits for St.-Denis we observe systematic residuals around 1001.10 and $1003.70 \mathrm{~cm}^{-1}$, which are due to water vapour lines. However, fitting $\mathrm{H}_{2} \mathrm{O}$ profiles first to use the resulting daily a priori profiles in the $\mathrm{O}_{3}$ retrieval, or excluding the two small regions from our micro-window, did not affect the retrievals significantly.

We obtain about 5 degrees of freedom for $\mathrm{O}_{3}$ at both sites. It is therefore possible to distinguish 5 independent layers with good sensitivity, namely 2 layers in the troposphere (2.2 / 0.1 to 8.2 and 8.2 to $17.8 \mathrm{~km}$ ), and 3 layers in the stratosphere (17.8 to $23.8,23.8$ to 31.0 and 31.0 to $100 \mathrm{~km}$ ).

\subsubsection{Methane $\left(\mathrm{CH}_{4}\right)$}

The $\mathrm{CH}_{4}$ a priori profile was based on available data from the Halogen Occultation Experiment (HALOE), onboard the Upper Atmosphere Research Satellite (UARS), launched in September 1991 (http://haloedata.larc.nasa.gov/home). $\mathrm{CH}_{4}$ retrievals from HALOE have been validated by Park et al. (1996). We took a six year weighted mean of all HALOE (version 19) vertical profiles from 2000 to 2005 within the $15^{\circ}$ longitude and $10^{\circ}$ latitude rectangle around Ile de $\mathrm{La}$
Réunion, with weights defined by the errors that are provided together with the HALOE profiles.

The resulting weighted mean profile covers the range 14 to $80 \mathrm{~km}$, so below and above these altitudes we have extrapolated the profile by repeating the values at 14 and $80 \mathrm{~km}$, respectively. In contrast to all other retrieved molecules we have used non constant diagonal elements to construct $\mathbf{S}_{a}$. This is done, because it significantly reduces the large oscillations in the retrieved profiles that emerge when using constant uncertainties. The values are calculated out of the same HALOE profiles as used to determine the a priori profile. The obtained variabilities (in percentage) from 14.2 to $78.4 \mathrm{~km}$ are then extrapolated to the complete altitude range by repeating the first and last value. The offdiagonal elements are defined by a Gaussian distribution having a HWHM of $5 \mathrm{~km}$ and finally the matrix is transformed into squared volume mixing ratio units.

Figure 3 shows the multiple micro-window fit of $\mathrm{CH}_{4}$ from a single spectrum on 16 October 2002 and 12 October 2004 at Maïdo and St.-Denis, respectively, together with the residuals, computed as measured minus simulated transmission. Note that the retrieved profiles slightly oscillate near the surface.

As the number of degrees of freedom is about 2 at both sites, we manage to resolve two independent partial columns of $\mathrm{CH}_{4}$, namely 2.2 to $11.8 \mathrm{~km}$ and 11.8 to $100 \mathrm{~km}$ for Maïdo and 0.1 to 8.2 and 8.2 to $100 \mathrm{~km}$ for St.-Denis. 

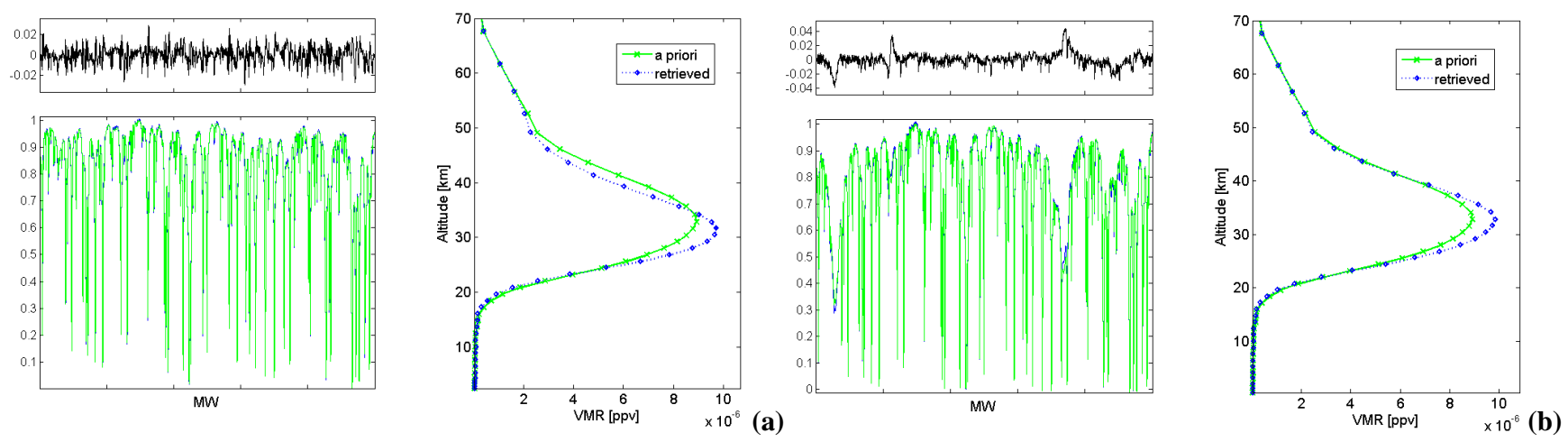

Fig. 2. Single micro-window (1000.00-1005.00 $\mathrm{cm}^{-1}$ ) fit of $\mathrm{O}_{3}$ plus interfering species from a single spectrum on (a) 13 October 2002 at Maïdo and on (b) 15 October 2004 at St.-Denis. Measured (blue) and simulated spectra (green) are shown (left lower plot), together with the residuals (left upper plot), computed as measured minus simulated. The right plot shows the a priori (green crosses) and retrieved (blue diamonds) profile.
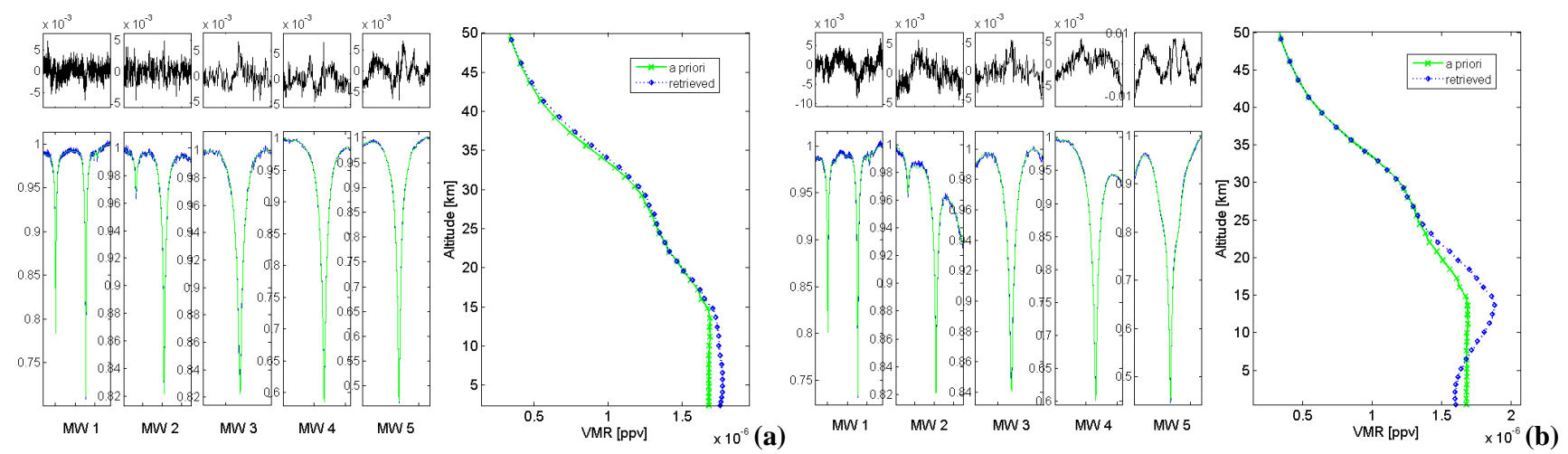

Fig. 3. Multiple micro-window (MW1: 2613.70-2615.40, MW2: 2650.60-2651.30, MW3: 2835.50-2835.80, MW4: 2903.60-2904.03, and MW5: 2921.00-2921.60 $\mathrm{cm}^{-1}$ ) fit of $\mathrm{CH}_{4}$ plus interfering species from a single spectrum on (a) 16 October 2002 at Maïdo and on (b) 12 October 2004 at St.-Denis. Measured (blue) and simulated spectra (green) are shown (left lower plot), together with the residuals (left upper plot), computed as measured minus simulated. The right plot shows the a priori (green crosses) and retrieved (blue diamonds) profile.

\subsubsection{Nitrous oxide $\left(\mathrm{N}_{2} \mathrm{O}\right)$}

For the $\mathrm{N}_{2} \mathrm{O}$ a priori profile we used the 1976 U.S. Standard profile (U.S. NOAA, 1976) scaled with a yearly factor of $0.25 \%$, to account for the slight yearly $\mathrm{N}_{2} \mathrm{O}$ increase observed by Zander et al. (2005).

Figure 4 shows the multiple micro-window fit of $\mathrm{N}_{2} \mathrm{O}$ from a single spectrum on 16 October 2002 and 12 October 2004 at Maïdo and St.-Denis, respectively, together with the residuals, computed as measured minus simulated transmission.

As the number of degrees of freedom for $\mathrm{N}_{2} \mathrm{O}$ is about 3 for Maïdo as well as for St.-Denis, three independent partial columns can be distinguished, in particular from $2.2 / 0.1$ to 4.6, from 4.6 to 15.4 and from 15.4 to $100 \mathrm{~km}$.

\subsubsection{Carbon monoxide (CO)}

The $\mathrm{CO}$ a priori profile has been based on available data from the MOPITT space-borne instrument onboard the EOS-TERRA satellite, which was launched in December 1999 (http://terra.nasa.gov/About/MOPITT/index.php). CO retrievals from MOPITT have been validated by Emmons et al. (2004). Our CO a priori profile is a five year mean of all MOPITT vertical profiles (version L2V5) from 2000 to 2004 within $15^{\circ}$ longitude and $10^{\circ}$ latitude around the location of our observations. We only used daytime measurements for which the solar zenith angle was smaller than $80^{\circ}$. The thus obtained mean a priori profile from 0 to $14 \mathrm{~km}$ was then completed with the U.S. Standard Atmosphere (1976) values from 16 to $100 \mathrm{~km}$.

Figure 5 shows the multiple micro-window fit of $\mathrm{CO}$ from a single spectrum on 19 October 2002 and 12 October 2004 at Maïdo and St.-Denis, respectively, together with the residuals, computed as measured minus simulated transmission. 

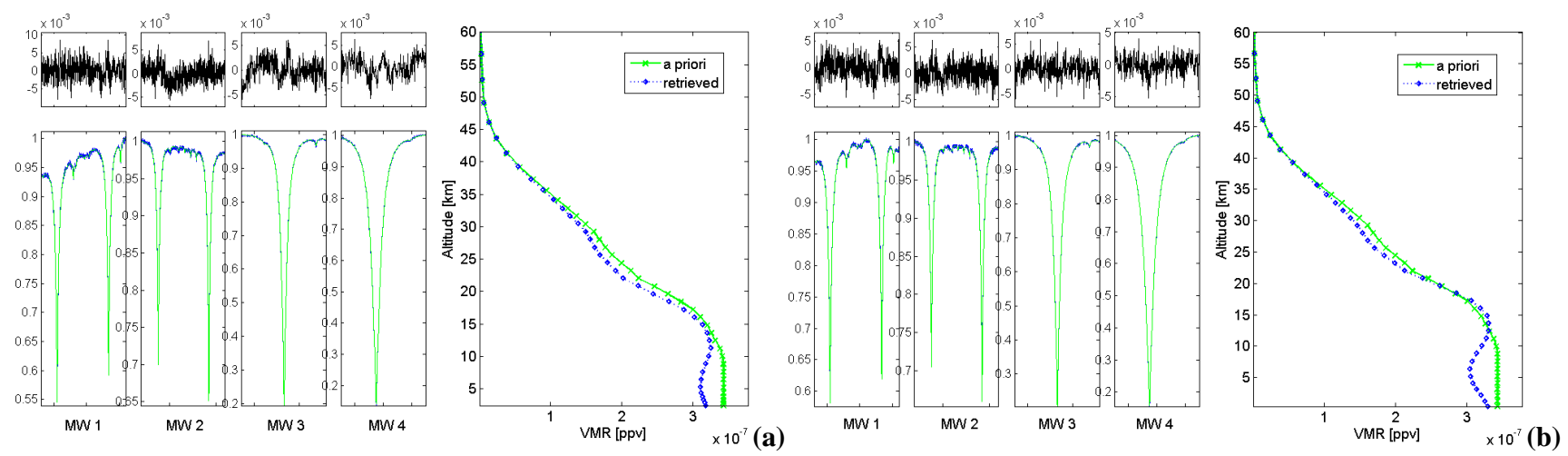

Fig. 4. Multiple micro-window (MW1: 2481.30-2482.60, MW2: 2526.40-2528.20, MW3: 2537.85-2538.80, and MW4: 2540.10$2540.70 \mathrm{~cm}^{-1}$ ) fit of $\mathrm{N}_{2} \mathrm{O}$ plus interfering species from a single spectrum on (a) 16 October 2002 at Maïdo and on (b) 12 October 2004 at St.-Denis. Measured (blue) and simulated spectra (green) are shown (left lower plot), together with the residuals (left upper plot), computed as measured minus simulated. The right plot shows the a priori (green crosses) and retrieved (blue diamonds) profile.
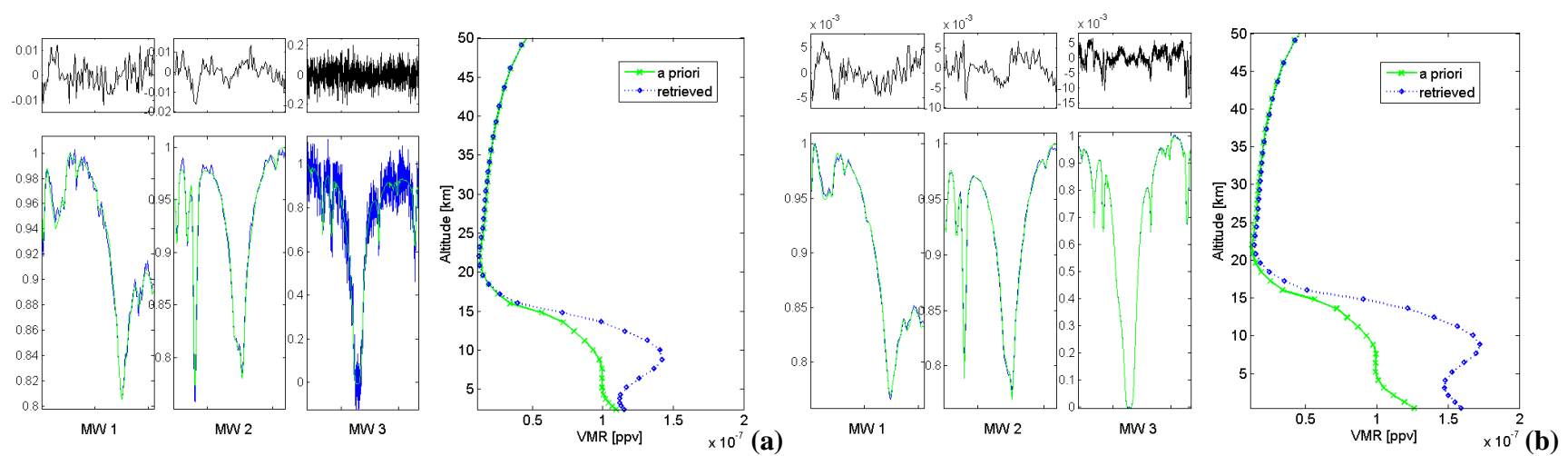

Fig. 5. Multiple micro-window (MW1: 2057.70-2057.91, MW2: 2069.55-2069.72, and MW3: 2157.40-2159.35 $\mathrm{cm}^{-1}$ ) fit of CO plus interfering species from a single spectrum on (a) 19 October 2002 at Maïdo and on (b) 12 October 2004 at St.-Denis. Measured (blue) and simulated spectra (green) are shown (left lower plot), together with the residuals (left upper plot), computed as measured minus simulated. The right plot shows the a priori (green crosses) and retrieved (blue diamonds) profile.

From the first figure it is clear that for the 2002 spectra the $\mathrm{CO}$ micro-windows are contaminated by noise, due to the bad filters choice.

The DOFS for CO in our measurements is about 2.7, providing us with just 2 independent layers, namely 2.2 to $10.6 \mathrm{~km}$ and 10.6 to $100 \mathrm{~km}$ for Maïdo and 0.1 to 9.4 and 9.4 to $100 \mathrm{~km}$ for St.-Denis.

\subsubsection{Ethane $\left(\mathrm{C}_{2} \mathrm{H}_{6}\right)$}

Between 12 and $30 \mathrm{~km}$, the a priori profile for $\mathrm{C}_{2} \mathrm{H}_{6}$ was adopted from Cronn and Robinson (1979) and above $30 \mathrm{~km}$ from Rudolph and Ehhalt (1981). Below $12 \mathrm{~km}$ the a priori volume mixing ratio was set constant at $7 \times 10^{-10} \mathrm{ppv}$.

Figure 6 shows the single micro-window fit of $\mathrm{C}_{2} \mathrm{H}_{6}$ from a single spectrum on 14 October 2002 and 9 October 2004 at Maïdo and St.-Denis, respectively, together with the residuals, computed as measured minus simulated.

Since we obtain about 1.6 degrees of freedom, we consider only total column amounts of $\mathrm{C}_{2} \mathrm{H}_{6}$.

\subsubsection{Hydrogen chloride $(\mathrm{HCl})$}

The $\mathrm{HCl}$ a priori profile between 16 and $60 \mathrm{~km}$ was created from HALOE (version 19) observations, following the same approach as for $\mathrm{CH}_{4}$. $\mathrm{HCl}$ retrievals from HALOE have been validated by Russell et al. (1996a). Below $16 \mathrm{~km}$ the profile was completed with values from Smith (1982) and above $60 \mathrm{~km}$ a constant mixing ratio was adopted, which was equal to the upper value of the weighted mean HALOE profile.

Figure 7 shows the multiple micro-window fit of $\mathrm{HCl}$ from a single spectrum on 16 October 2002 and 15 October 2004 at Maïdo and St.-Denis, respectively, together with the residuals, computed as measured minus simulated transmission. Note that around $25 \mathrm{~km}$ the retrieved profile differs strongly from the a priori profile. Such deviations are observed for all our $\mathrm{HCl}$ measurements, but up to now we did not manage to find the origin of this structure.

Again, we can only derive total column amounts, because the number of degrees of freedom for $\mathrm{HCl}$ is about 1.3 at both sites. 

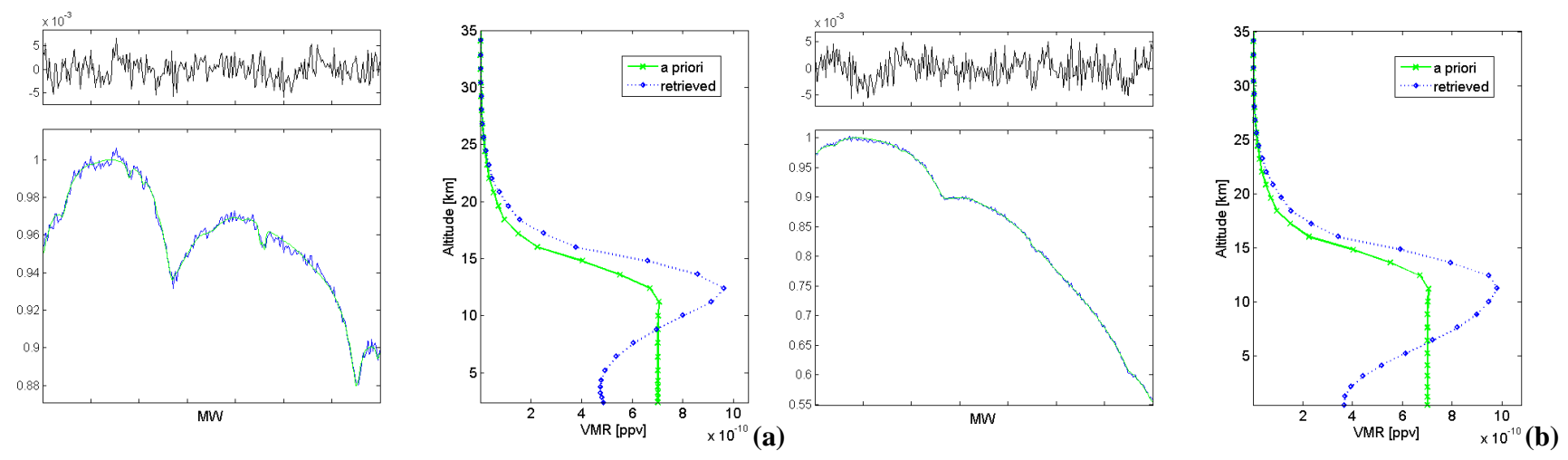

Fig. 6. Single micro-window (2976.50-2977.20 $\mathrm{cm}^{-1}$ ) fit of $\mathrm{C}_{2} \mathrm{H}_{6}$ plus interfering species from a single spectrum on (a) 14 October 2002 at Maïdo and on (b) 9 October 2004 at St.-Denis. Measured (blue) and simulated spectra (green) are shown (left lower plot), together with the residuals (left upper plot), computed as measured minus simulated. The right plot shows the a priori (green crosses) and retrieved (blue diamonds) profile.
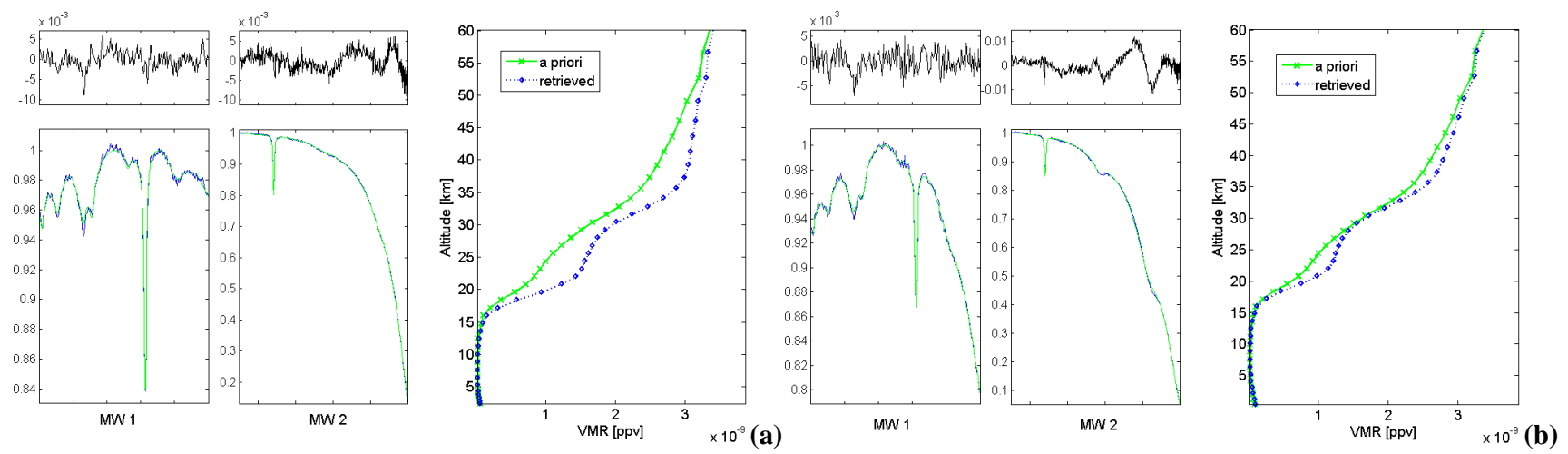

Fig. 7. Multiple micro-window (MW1: 2843.30-2843.80 and MW2: 2925.70-2926.60 $\mathrm{cm}^{-1}$ ) fit of HCl plus interfering species from a single spectrum on (a) 16 October 2002 at Maïdo and on (b) 15 October 2004 at St.-Denis. Measured (blue) and simulated spectra (green) are shown (left lower plot), together with the residuals (left upper plot), computed as measured minus simulated. The right plot shows the a priori (green crosses) and retrieved (blue diamonds) profile.

\subsubsection{Hydrogen fluoride (HF)}

The HF a priori profile between 14 and $60 \mathrm{~km}$ was derived from HALOE (version 19) observations, as was done for $\mathrm{HCl}$. HF retrievals from HALOE have been validated by Russell et al. (1996b). The profile was extrapolated with constant values above and below that altitude range, by repeating the volume mixing ratio at 60 and $14 \mathrm{~km}$, respectively.

Figure 8 shows the single micro-window fit of HF from a single spectrum on 13 October 2002 and 11 October 2004 at Maïdo and St.-Denis, respectively, together with the residuals, computed as measured minus simulated transmission.

The 1.5 degrees of freedom tell us that we can only determine the total columns of HF.

\subsubsection{Nitric acid $\left(\mathrm{HNO}_{3}\right)$}

For the creation of an $\mathrm{HNO}_{3}$ reference profile, we used data from the SMR instrument, onboard the satellite Odin, launched in February 2001 (http://diamond.rss.chalmers.se/
Odin). $\mathrm{HNO}_{3}$ retrievals from Odin have been validated by Urban et al. (2005). In particular, we calculated a five year weighted mean, from 2001 to 2005, of all Odin/SMR profiles (version 2.0) within a $1500 \mathrm{~km}$ radius around St.-Denis, with weights defined by the errors on the Odin profiles. This gave us representative a priori values between 16 and $36 \mathrm{~km}$. Below and above these altitudes we completed the profile with a seasonal mean climatology for the $0^{\circ}-20^{\circ} \mathrm{S}$ latitude band in the period September-November 2002 from the Michelson Interferometer for Passive Atmospheric Sounding (MIPAS) onboard ESA's Envisat satellite, launched in March 2002 (http://envisat.esa.int/instruments/mipas/index.html). $\mathrm{HNO}_{3}$ retrievals from MIPAS have been validated by Oelhaf et al. (2004) and Wang et al. (2007).

Figure 9 shows the single micro-window fit of $\mathrm{HNO}_{3}$ from a single spectrum on 16 October 2002 and 21 October 2004 at Maïdo and St.-Denis, respectively, together with the residuals, computed as measured minus simulated transmission.

For $\mathrm{HNO}_{3}$ we get about 1 degree of freedom, so again only total column amounts can be obtained. 

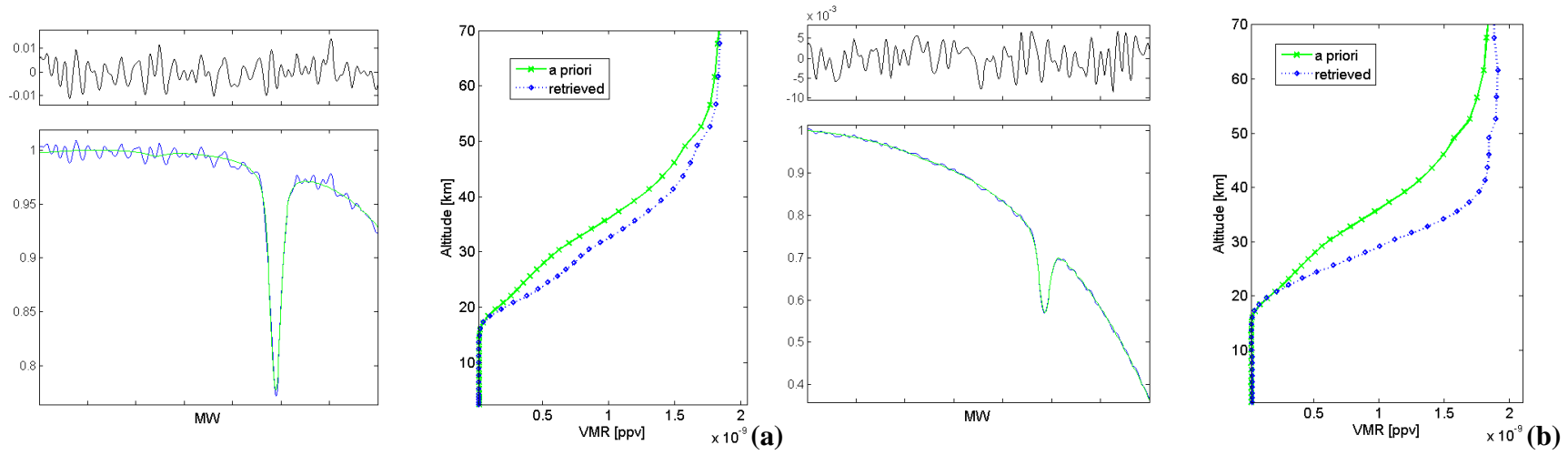

Fig. 8. Single micro-window (4038.70-4039.05 $\mathrm{cm}^{-1}$ ) fit of HF plus interfering species from a single spectrum on (a) 13 October 2002 at Maïdo and on (b) 11 October 2004 at St.-Denis. Measured (blue) and simulated spectra (green) are shown (left lower plot), together with the residuals (left upper plot), computed as measured minus simulated. The right plot shows the a priori (green crosses) and retrieved (blue diamonds) profile.
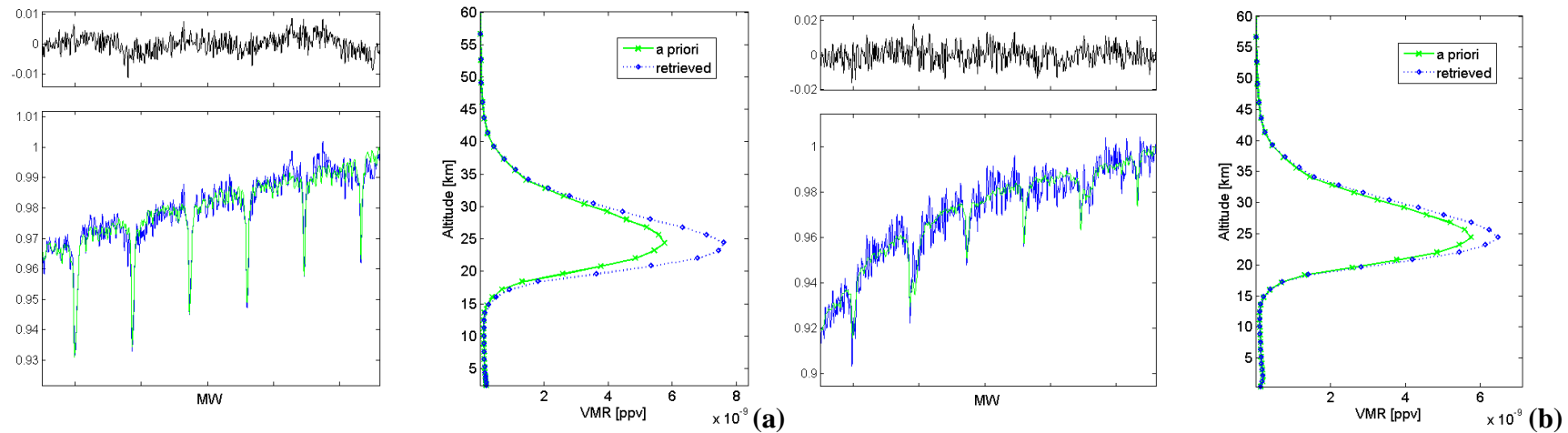

Fig. 9. Single micro-window $\left(872.25-874.80 \mathrm{~cm}^{-1}\right)$ fit of $\mathrm{HNO}_{3}$ plus interfering species from a single spectrum on (a) 16 October 2002 at Maïdo and on (b) 21 October 2004 at St.-Denis. Measured (blue) and simulated spectra (green) are shown (left lower plot), together with the residuals (left upper plot), computed as measured minus simulated. The right plot shows the a priori (green crosses) and retrieved (blue diamonds) profile.

\section{Error budget evaluations}

\subsection{Adopted approach}

Using the formalism described in Rodgers (2000) - assuming a linearization of the forward and inverse model about some reference state and spectrum, respectively - the difference between the retrieved and the real state of the atmosphere can be written as

$\mathbf{x}_{r}-\mathbf{x}=(\mathbf{A}-\mathbf{I})\left(\mathbf{x}-\mathbf{x}_{a}\right)+\mathbf{G}_{y} \mathbf{K}_{b}\left(\mathbf{b}-\mathbf{b}_{r}\right)+\mathbf{G}_{y}\left(\mathbf{y}-\mathbf{y}_{r}\right),(2)$

where $\mathbf{A}$ is the averaging kernel matrix as defined in Sect. 3.3, I the identity matrix, $\mathbf{G}_{y}$ the gain matrix representing the sensitivity of the retrieved parameters to the measurement, $\mathbf{K}_{b}$ the sensitivity matrix of the spectrum to the forward model parameters $\mathbf{b}, \mathbf{b}_{r}$ the estimated model parameters, $\mathbf{y}$ the observed spectrum, and $\mathbf{y}_{r}$ the calculated spectrum corresponding to the retrieved state vector. The equation above splits the total error in the retrieved profile into three different error sources, i.e., the smoothing error, the forward model parameter error and the measurement error. In addition, we have determined the temperature and interfering species error as individual contributions to the total random error. Besides the random errors we must also consider the systematic errors due to uncertainties in the spectroscopic line parameters. More details about the evaluation of the individual contributions to the error budget are provided in the next sections.

\subsubsection{Smoothing error}

The smoothing error covariance is calculated as $(\mathbf{I}-\mathbf{A}) \mathbf{S}_{a}$ $(\mathbf{I}-\mathbf{A})^{t}$, where $\mathbf{S}_{a}$ is the a priori covariance matrix (see Sect. 3.2.1). In order to construct a realistic $\mathbf{S}_{a}$ matrix, we need information about the variability and covariances of an ensemble of real profiles. However, this information is not always available at all altitudes, obliging us to replace $\mathbf{S}_{a}$ with a Gaussian covariance matrix for example, for which we still have to estimate the natural variabilities and the inter-layer 


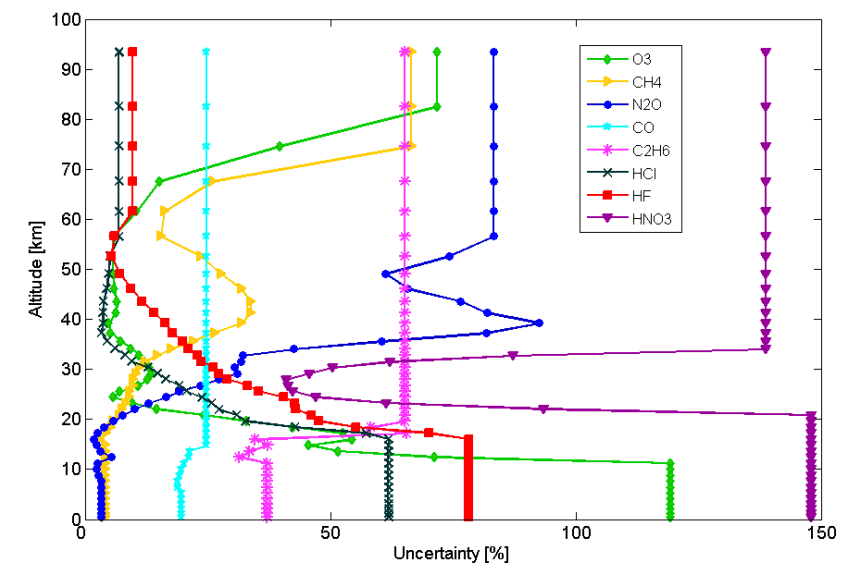

Fig. 10. A priori uncertainties (in \%) in the volume mixing ratios of each retrieved trace gas as a function of altitude, used for estimating the smoothing errors.

correlations based on real data. We have chosen these values such that $\mathbf{S}_{a}$ approaches the covariance matrix derived from satellite measurements within the available altitude range. For each species we calculated the weighted covariance matrix of all available vertical profiles measured by the specified satellite within the $15^{\circ}$ longitude and $10^{\circ}$ latitude rectangle around Ile de La Réunion, and used the resulting diagonal elements to create $\mathbf{S}_{a}$. The thus obtained variabilities that are reliable within a certain altitude range are then extrapolated to the complete altitude range $(0-100 \mathrm{~km})$ by repeating the lower- and uppermost values in percentage. The off-diagonal elements of $\mathbf{S}_{a}$ are defined by a Gaussian distribution having a HWHM which can be different for each molecule. The resulting matrix is then transformed into squared volume mixing ratio units. Table 2 summarizes which satellite data have been used for every trace gas, the altitude range in which they provide reliable values and the HWHM used to calculate the Gaussian off-diagonal elements of the $\mathbf{S}_{a}$ matrix. For more information about the satellite data used, we refer to Sect. 6.1. Figure 10 shows the resulting uncertainties in the a priori volume mixing ratios of each species as a function of altitude.

\subsubsection{Forward model parameter error}

We considered the random uncertainties in the forward model parameters, described in Sect. 3.1, to be mutually independent; hence we used a matrix $\mathbf{S}_{b}$ that is diagonal. For the wavenumber shift, background curve parameters, and ILS parameters, we adopted uncertainties of $10 \%, 10 \%$, and $20 \%$, respectively. The resulting errors on the retrieved target profile are then calculated as $\left(\mathbf{G}_{y} \mathbf{K}_{b}\right) \mathbf{S}_{b}\left(\mathbf{G}_{y} \mathbf{K}_{b}\right)^{t}$.
Table 2. Source information, altitude range of the obtained a priori variability vector and HWHM of the Gaussian off-diagonal elements of $\mathbf{S}_{a}$ for each molecule.

\begin{tabular}{lllc}
\hline Molecule & Source & $\begin{array}{l}\text { Altitude } \\
\text { range }[\mathrm{km}]\end{array}$ & $\begin{array}{c}\text { HWHM } \\
{[\mathrm{km}]}\end{array}$ \\
\hline $\mathbf{O}_{3}$ & HALOE & $10.6-86.8$ & 5 \\
$\mathbf{C H}_{4}$ & HALOE & $14.2-78.4$ & 6 \\
$\mathbf{N}_{2} \mathbf{O}$ & ACE & $7.0-58.8$ & 6 \\
$\mathbf{C O}$ & MOPITT & $4.6-16.6$ & 5 \\
$\mathbf{C}_{2} \mathbf{H}_{6}$ & ACE & $10.6-20.2$ & 3 \\
$\mathbf{H C l}$ & HALOE & $15.4-58.8$ & 7 \\
$\mathbf{H F}$ & HALOE & $15.4-64.4$ & 6 \\
$\mathbf{H N O}$ & Odin & $20.2-34.8$ & 4 \\
\hline
\end{tabular}

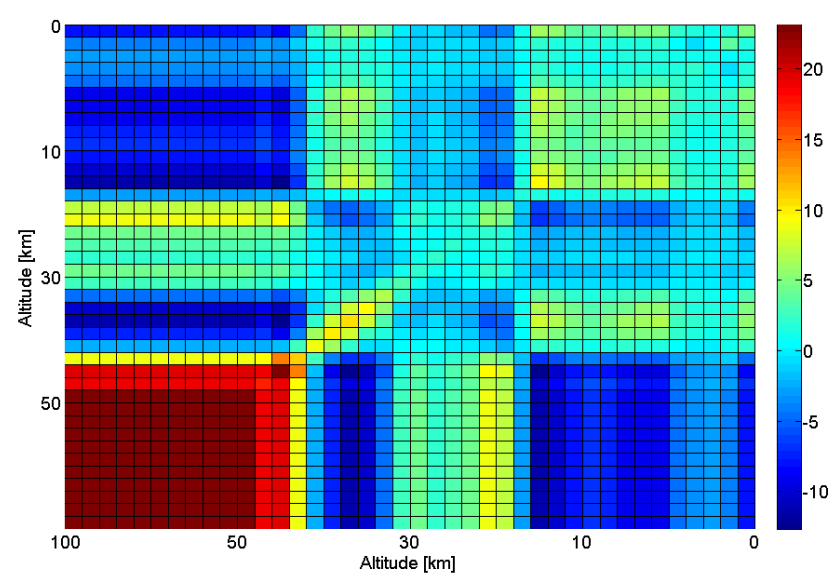

Fig. 11. Temperature covariance matrix (in $\mathrm{K}^{2}$ ) from NCEP and ECMWF temperature profiles at Ile de La Réunion in October 2004, used for estimating the temperature errors.

\subsubsection{Measurement error}

The uncertainties coming from the measurement noise are calculated as $\mathbf{G}_{y} \mathbf{S}_{\varepsilon} \mathbf{G}_{y}^{t}$, where $\mathbf{S}_{\varepsilon}$ is the measurement noise covariance matrix, defined as a diagonal matrix consisting of the squared noise in the observed spectra. These noise values have been determined for every fitted micro-window independently, as the root mean squared value (rms) of the differences between the observed and calculated spectrum within each bandpass.

\subsubsection{Temperature error}

The atmospheric temperature profile is a forward model parameter that is not fitted. Nevertheless, the associated uncertainties must be considered as well, because they influence the retrieved profiles via the temperature dependence of the absorption lines. The temperature error covariance matrix is calculated as $\left(\mathbf{G}_{y} \mathbf{K}_{T}\right) \mathbf{S}_{T}\left(\mathbf{G}_{y} \mathbf{K}_{T}\right)^{t}$, in which $\mathbf{S}_{T}$ is a realistic covariance matrix of the temperature profile uncertainties. 
Table 3. Summary of the error budgets (in \%) on the total $(2.2-100 \mathrm{~km})$ and partial columns (altitude ranges specified in km) for each target species retrieved from the Ile de La Réunion campaign data, for Maïdo 2002. The total and partial column amounts (in molecules/ $\mathrm{cm}^{2}$ ) and corresponding natural variabilities (in \%) are listed in the second and third columns, respectively.

\begin{tabular}{|c|c|c|c|c|c|c|c|c|c|c|c|}
\hline Molecule & $\begin{array}{l}\text { Column } \\
\text { amount } \\
{\left[\mathrm{molec} / \mathrm{cm}^{2}\right]}\end{array}$ & $\begin{array}{l}\text { Natural } \\
\text { variab. } \\
{[\%]}\end{array}$ & $\begin{array}{l}\text { Temp. } \\
\text { error } \\
{[\%]}\end{array}$ & $\begin{array}{l}\text { Interf. } \\
\text { species } \\
\text { error } \\
{[\%]}\end{array}$ & $\begin{array}{l}\text { FM } \\
\text { param. } \\
\text { error } \\
{[\%]}\end{array}$ & $\begin{array}{l}\text { Meas. } \\
\text { error } \\
{[\%]}\end{array}$ & $\begin{array}{l}\text { Smooth. } \\
\text { error } \\
{[\%]}\end{array}$ & $\begin{array}{l}\text { Total } \\
\text { random } \\
\text { error } \\
{[\%]}\end{array}$ & $\begin{array}{l}\text { Line } \\
\text { intens. } \\
\text { error } \\
{[\%]}\end{array}$ & $\begin{array}{l}\text { Air } \\
\text { broad. } \\
\text { error } \\
{[\%]}\end{array}$ & $\begin{array}{l}\text { Total } \\
\text { syst. } \\
\text { error } \\
{[\%]}\end{array}$ \\
\hline \multicolumn{12}{|l|}{$\mathbf{O}_{3}$} \\
\hline $2.2-100$ & $7.57 \times 10^{18}$ & 15.41 & 0.47 & 0.01 & 0.02 & 0.41 & 1.29 & 1.43 & 4.71 & 0.49 & 4.74 \\
\hline $2.2-8.2$ & $5.71 \times 10^{17}$ & 111.27 & 0.10 & 0.39 & 0.04 & 4.37 & 16.06 & 16.64 & 4.97 & 6.20 & 7.95 \\
\hline $8.2-17.8$ & $7.66 \times 10^{17}$ & 67.00 & 1.38 & 0.78 & 0.10 & 5.87 & 22.25 & 23.06 & 6.81 & 6.84 & 9.65 \\
\hline $17.8-23.8$ & $1.67 \times 10^{18}$ & 19.02 & 1.26 & 0.53 & 0.02 & 3.36 & 13.14 & 13.63 & 6.10 & 8.86 & 10.75 \\
\hline $23.8-31.0$ & $3.10 \times 10^{18}$ & 9.35 & 1.91 & 0.34 & 0.10 & 2.63 & 10.78 & 11.26 & 5.10 & 2.22 & 5.57 \\
\hline $31.0-100$ & $1.47 \times 10^{18}$ & 7.48 & 1.97 & 0.34 & 0.07 & 1.68 & 8.72 & 9.10 & 4.96 & 3.88 & 6.30 \\
\hline \multicolumn{12}{|l|}{$\mathbf{C H}_{4}$} \\
\hline $2.2-100$ & $2.86 \times 10^{19}$ & 3.15 & 0.87 & 0.01 & 0.09 & 0.16 & 0.58 & 1.06 & 19.61 & 3.44 & 19.91 \\
\hline $2.2-11.8$ & $2.14 \times 10^{19}$ & 3.67 & 0.49 & 0.05 & 0.23 & 0.32 & 0.54 & 0.82 & 20.15 & 1.66 & 20.21 \\
\hline $11.8-100$ & $7.16 \times 10^{18}$ & 3.75 & 2.04 & 0.10 & 0.75 & 0.62 & 0.82 & 2.41 & 18.01 & 17.73 & 25.28 \\
\hline \multicolumn{12}{|l|}{$\mathbf{N}_{2} \mathbf{O}$} \\
\hline $2.2-100$ & $5.05 \times 10^{18}$ & 2.51 & 0.12 & 0.02 & 0.13 & 0.09 & 0.17 & 0.26 & 4.61 & 0.84 & 4.69 \\
\hline $2.2-4.6$ & $1.34 \times 10^{18}$ & 3.24 & 0.99 & 0.20 & 0.06 & 0.69 & 2.08 & 2.41 & 4.41 & 8.73 & 9.78 \\
\hline $4.6-15.4$ & $3.12 \times 10^{18}$ & 2.76 & 0.10 & 0.06 & 0.04 & 0.37 & 1.28 & 1.34 & 4.65 & 4.03 & 6.15 \\
\hline $15.4-100$ & $5.86 \times 10^{17}$ & 5.49 & 0.83 & 0.08 & 1.43 & 1.06 & 1.38 & 2.40 & 5.05 & 5.80 & 7.69 \\
\hline \multicolumn{12}{|l|}{$\mathrm{CO}$} \\
\hline $2.2-100$ & $1.76 \times 10^{18}$ & 15.57 & 0.94 & 0.01 & 0.16 & 6.37 & 0.32 & 6.45 & 4.73 & 0.37 & 4.74 \\
\hline $2.2-10.6$ & $1.39 \times 10^{18}$ & 17.13 & 1.29 & 0.01 & 0.12 & 9.68 & 0.98 & 9.82 & 4.89 & 1.85 & 5.22 \\
\hline $10.6-100$ & $3.75 \times 10^{17}$ & 19.03 & 0.36 & 0.02 & 0.33 & 12.10 & 3.58 & 12.63 & 4.30 & 5.19 & 6.74 \\
\hline \multicolumn{12}{|l|}{$\mathbf{C}_{2} \mathbf{H}_{6}$} \\
\hline $2.2-100$ & $9.14 \times 10^{15}$ & 23.11 & 0.62 & 0.67 & 0.32 & 1.02 & 0.88 & 1.66 & 19.96 & 7.27 & 21.24 \\
\hline \multicolumn{12}{|l|}{$\mathrm{HCl}$} \\
\hline $2.2-100$ & $3.15 \times 10^{15}$ & 20.95 & 0.28 & 0.03 & 0.49 & 0.91 & 7.11 & 7.19 & 1.32 & 3.04 & 3.32 \\
\hline \multicolumn{12}{|l|}{ HF } \\
\hline $2.2-100$ & $1.04 \times 10^{15}$ & 24.48 & 0.22 & 0.01 & 0.33 & 1.61 & 5.81 & 6.04 & 4.86 & 0.98 & 4.96 \\
\hline \multicolumn{12}{|l|}{$\mathrm{HNO}_{3}$} \\
\hline $2.2-100$ & $1.03 \times 10^{16}$ & 64.50 & 0.74 & 0.01 & 0.72 & 1.21 & 21.13 & 21.19 & 14.70 & 2.22 & 14.87 \\
\hline
\end{tabular}

The factor $\left(\mathbf{G}_{y} \mathbf{K}_{T}\right)$, containing the partial derivatives of the retrieval to the temperatures, has been determined by repeating the retrieval with temperature profiles that are slightly perturbed at all altitudes separately. Our estimation of $\mathbf{S}_{T}$ is based on the differences between the NCEP and ECMWF temperature profiles for Ile de La Réunion in the period August-October 2004. Its elements are calculated as

$$
\begin{array}{r}
\mathbf{S}_{T}(i, j)=E\left[\left(\mathbf{T}_{\mathrm{NCEP}}(i)-\mathbf{T}_{\mathrm{ECMWF}}(i)\right) *\right. \\
\left.\left(\mathbf{T}_{\mathrm{NCEP}}(j)-\mathbf{T}_{\mathrm{ECMWF}}(j)\right)\right] .
\end{array}
$$

This matrix is visualized in Fig. 11. The 41 profile layers from high to low altitude are defined as follows: from 100 to $50 \mathrm{~km}$ by steps of $5 \mathrm{~km}$, from 50 to $10 \mathrm{~km}$ by steps of $2 \mathrm{~km}$ and from $10 \mathrm{~km}$ to the surface by steps of $1 \mathrm{~km}$. As the NCEP profiles do not reach higher than about $54 \mathrm{~km}$, we have repeated the covariances at $50 \mathrm{~km}$ for all altitudes above.

\subsubsection{Interfering species error}

The error on the retrieval of a target gas coming from the uncertainties in the vertical distributions of the interfering species has been calculated by performing retrievals using an ensemble of vertical profiles of every significant interferer separately, representing the uncertainties in its a priori profile (Sussmann and Borsdorff, 2007; Connor et al., 2008). Consequently we derive an error covariance matrix based on the thus obtained set of retrieved target profile differences relative to the reference profile, which represents the contribution of the interfering species uncertainties to the random error.

We have observed that when considering only the total column uncertainties of the interfering species, this error component is clearly underestimated in some cases. 
Table 4. Summary of the error budgets (in \%) on the total $(0.05-100 \mathrm{~km})$ and partial columns (altitude ranges specified in $\mathrm{km})$ for each target species retrieved from the Ile de La Réunion campaign data, for St.-Denis 2004. The total and partial column amounts (in molecules/cm ${ }^{2}$ ) and corresponding natural variabilities (in \%) are listed in the second and third columns, respectively.

\begin{tabular}{|c|c|c|c|c|c|c|c|c|c|c|c|}
\hline Molecule & $\begin{array}{l}\text { Column } \\
\text { amount } \\
{\left[\mathrm{molec} / \mathrm{cm}^{2}\right]}\end{array}$ & $\begin{array}{l}\text { Natural } \\
\text { variab. } \\
{[\%]}\end{array}$ & $\begin{array}{l}\text { Temp. } \\
\text { error } \\
{[\%]}\end{array}$ & $\begin{array}{l}\text { Interf. } \\
\text { species } \\
\text { error } \\
{[\%]}\end{array}$ & $\begin{array}{l}\text { FM } \\
\text { param. } \\
\text { error } \\
{[\%]}\end{array}$ & $\begin{array}{l}\text { Meas. } \\
\text { error } \\
{[\%]}\end{array}$ & $\begin{array}{l}\text { Smooth. } \\
\text { error } \\
{[\%]}\end{array}$ & $\begin{array}{l}\text { Total } \\
\text { random } \\
\text { error } \\
{[\%]}\end{array}$ & $\begin{array}{l}\text { Line } \\
\text { intens. } \\
\text { error } \\
{[\%]}\end{array}$ & $\begin{array}{l}\text { Air } \\
\text { broad. } \\
\text { error } \\
{[\%]}\end{array}$ & $\begin{array}{l}\text { Total } \\
\text { syst. } \\
\text { error } \\
{[\%]}\end{array}$ \\
\hline \multicolumn{12}{|l|}{$\mathbf{O}_{3}$} \\
\hline $0.05-100$ & $7.78 \times 10^{18}$ & 14.43 & 0.50 & 0.12 & 0.01 & 0.31 & 0.57 & 0.82 & 4.68 & 0.38 & 4.69 \\
\hline $0.05-8.2$ & $6.46 \times 10^{17}$ & 106.23 & 0.09 & 1.02 & 0.02 & 3.84 & 10.71 & 11.42 & 5.60 & 4.51 & 7.19 \\
\hline $8.2-17.8$ & $6.80 \times 10^{17}$ & 61.72 & 1.86 & 1.38 & 0.09 & 4.75 & 13.53 & 14.53 & 5.04 & 4.68 & 6.87 \\
\hline $17.8-23.8$ & $1.82 \times 10^{18}$ & 19.38 & 1.59 & 1.65 & 0.04 & 3.23 & 8.88 & 9.73 & 5.20 & 7.49 & 9.12 \\
\hline $23.8-31.0$ & $3.05 \times 10^{18}$ & 9.31 & 2.37 & 1.48 & 0.10 & 2.50 & 5.97 & 7.05 & 4.31 & 1.74 & 4.65 \\
\hline $31.0-100$ & $1.59 \times 10^{18}$ & 7.32 & 1.89 & 0.92 & 0.10 & 2.39 & 6.60 & 7.33 & 5.18 & 3.91 & 6.49 \\
\hline \multicolumn{12}{|l|}{$\mathrm{CH}_{4}$} \\
\hline $0.05-100$ & $3.58 \times 10^{19}$ & 3.06 & 1.08 & 0.48 & 0.01 & 0.25 & 0.18 & 1.22 & 19.94 & 3.17 & 20.19 \\
\hline $0.05-8.2$ & $2.23 \times 10^{19}$ & 3.78 & 1.17 & 0.76 & 0.21 & 0.70 & 0.58 & 1.68 & 20.69 & 6.19 & 21.60 \\
\hline $8.2-100$ & $1.35 \times 10^{19}$ & 3.43 & 0.94 & 0.94 & 0.39 & 0.68 & 0.60 & 1.66 & 18.69 & 18.49 & 26.29 \\
\hline \multicolumn{12}{|l|}{$\mathbf{N}_{2} \mathbf{O}$} \\
\hline $0.05-100$ & $6.63 \times 10^{18}$ & 2.44 & 0.18 & 0.02 & 0.09 & 0.08 & 0.15 & 0.27 & 4.59 & 0.79 & 4.66 \\
\hline $0.05-4.6$ & $2.89 \times 10^{18}$ & 3.17 & 0.80 & 0.16 & 0.14 & 0.32 & 0.89 & 1.25 & 4.64 & 6.88 & 8.30 \\
\hline $4.6-15.4$ & $3.11 \times 10^{18}$ & 2.75 & 0.34 & 0.13 & 0.14 & 0.25 & 0.91 & 1.02 & 4.62 & 7.17 & 8.53 \\
\hline $15.4-100$ & $6.26 \times 10^{17}$ & 5.34 & 0.20 & 0.13 & 1.04 & 0.53 & 1.20 & 1.69 & 4.36 & 4.82 & 6.50 \\
\hline \multicolumn{12}{|l|}{$\mathrm{CO}$} \\
\hline $0.05-100$ & $2.96 \times 10^{18}$ & 14.95 & 0.69 & 0.05 & 0.17 & 0.46 & 0.37 & 0.93 & 3.05 & 0.16 & 3.06 \\
\hline $0.05-9.4$ & $2.32 \times 10^{18}$ & 16.80 & 0.73 & 0.04 & 0.14 & 0.65 & 1.06 & 1.45 & 2.92 & 1.02 & 3.09 \\
\hline $9.4-100$ & $6.38 \times 10^{17}$ & 18.51 & 0.54 & 0.15 & 0.38 & 2.09 & 3.79 & 4.38 & 3.57 & 2.97 & 4.65 \\
\hline \multicolumn{12}{|l|}{$\mathbf{C}_{2} \mathbf{H}_{6}$} \\
\hline $\begin{array}{l}0.05-100 \\
\mathbf{H C l}\end{array}$ & \multicolumn{10}{|c|}{$\mathrm{HCl}$} & 14.98 \\
\hline $0.05-100$ & $3.16 \times 10^{15}$ & 22.63 & 0.17 & 0.67 & 0.41 & 2.27 & 10.95 & 11.21 & 2.50 & 4.00 & 4.72 \\
\hline \multicolumn{12}{|l|}{ HF } \\
\hline $0.05-100$ & $1.32 \times 10^{15}$ & 26.51 & 0.15 & 0.12 & 0.19 & 1.96 & 13.57 & 13.71 & 3.53 & 0.20 & 3.54 \\
\hline \multicolumn{12}{|l|}{$\mathrm{HNO}_{3}$} \\
\hline $0.05-100$ & $9.58 \times 10^{15}$ & 60.40 & 1.28 & 0.27 & 0.87 & 2.71 & 25.61 & 25.80 & 33.32 & 7.00 & 34.05 \\
\hline
\end{tabular}

\subsubsection{Line intensity and pressure broadening error}

In addition to the random error budget, we determined the systematic error in the retrievals originating from the uncertainties in the spectroscopic line intensities and in the pressure broadening coefficients. We therefore performed retrievals with perturbed spectroscopic line intensities and broadening coefficients of the target lines within our microwindows. The perturbation of these line parameters is based on their maximum uncertainties as given by Rothman et al. (2005). While for all molecules, except for $\mathrm{CH}_{4}$ and $\mathrm{HNO}_{3}$, these uncertainties are specified within certain limits, for $\mathrm{CH}_{4}$ and $\mathrm{HNO}_{3}$ we assumed the uncertainties on the line intensities to be 20 and $25 \%$, respectively, as they are only specified to be larger than or equal to $20 \%$. The corresponding systematic error covariance matrices are then calculated based on the differences between the thus retrieved vertical profiles and the originally retrieved profiles.

\subsection{Discussion}

The estimated error values for representative Maïdo and St.Denis spectra, recorded at solar zenith angles between 40 and $65^{\circ}$, are summarized in Table 3 and Table 4 , respectively. Note that we only show the error values for the 2004 campaign at St.-Denis, because the 2002 campaign at this location yields similar values.

The systematic errors are generally dominated by the uncertainties in the line intensities. For all species, they are very similar at both locations. This is a logical consequence of the fact that we use the same spectroscopic database and the same retrieval strategy for both sites. 
In particular, the systematic errors are especially high for $\mathrm{CH}_{4}, \mathrm{HNO}_{3}$ and $\mathrm{C}_{2} \mathrm{H}_{6}$, because of strong uncertainties in their spectroscopic line parameters.

It can also be seen in Tables 3 and 4 that the uncertainties on the air broadening coefficients significantly affect the errors on the profile retrieval, or the partial column errors, but that they have a smaller impact on the total column errors, as one might expect. Only in the case of $\mathrm{HCl}$, the error on the total column due to air broadening coefficient uncertainties is larger than the one due to line intensity uncertainties.

Regarding the total column smoothing error, we observe that it is larger for the stratospheric species than for the tropospheric species, at both sites. Generally it becomes larger with decreasing DOFS, and when the true profile has more vertical structure. For most molecules, we see slightly larger PC smoothing errors at Maïdo, where the DOFS is slightly smaller. If the DOFS exceeds one, the smoothing error is larger for the independent partial columns than it is for the total column. The smoothing error is highest for the partial columns in which the species' profile has more vertical structure. For the stratospheric species, the smoothing error is the dominant contribution to the random error. For the other species, the main error source may vary.

Only in the case of $\mathrm{CO}$ and $\mathrm{C}_{2} \mathrm{H}_{6}$ at Maïdo the measurement noise is the dominant random error contribution. $\mathrm{C}_{2} \mathrm{H}_{6}$ is a very weak signature, making the SNR very small. As to CO, we remind the reader (see Sect. 2) that in 2002 at Maïdo, we made a less appropriate choice of optical filter and detector for the observation of the spectral range in which the CO micro-windows are located, causing a lower SNR and therefore a larger measurement error. The measurement error listed in Table 4 for CO at St.-Denis represents the nominal case.

The temperature error is more important when the lower state energies of the absorbing lines in the micro-windows become higher, which is the case for example for some $\mathrm{CH}_{4}$ and $\mathrm{O}_{3}$ lines. It is quite similar at Maïdo and St.-Denis.

The error due to interfering species uncertainties is dominated by the uncertainties on the $\mathrm{HDO}$ and $\mathrm{H}_{2} \mathrm{O}$ profiles. That explains why it is an important error source for species with strong $\mathrm{H}_{2} \mathrm{O}$ and/or $\mathrm{HDO}$ interfering lines, like $\mathrm{O}_{3}, \mathrm{CH}_{4}, \mathrm{HCl}$ and $\mathrm{C}_{2} \mathrm{H}_{6}$. As all other interfering species uncertainties have a negligible impact on the target species, we only included the error budgets due to uncertainties on $\mathrm{H}_{2} \mathrm{O}$ and/or HDO in Tables 3 and 4.

We see that in all cases this error is larger at the near sea level site St.-Denis than at the high-altitude site Maïdo, confirming the fact that the mountain site is much less affected by the high humidity in the (sub)tropics. Actually the mean $\mathrm{H}_{2} \mathrm{O}$ column amount observed above Maïdo during our first campaign is about $1.5 \times 10^{22}$ molecules $/ \mathrm{cm}^{2}$, while above St.Denis it is about $7 \times 10^{22}$ molecules $/ \mathrm{cm}^{2}$, respectively! The interfering species error on the total columns is below $0.7 \%$ for all cases at Maïdo, whereas it rises to about $2.2 \%$ for $\mathrm{C}_{2} \mathrm{H}_{6}$ at St.-Denis.
The forward model parameter error never is the dominant error source, except for the partial column of $\mathrm{N}_{2} \mathrm{O}$ above Maïdo, above $15.4 \mathrm{~km}$. This error source is similar at both measurement stations.

It is important to note that in all cases the total random errors are smaller than the species' natural variability, except for the upper two partial columns of $\mathrm{O}_{3}$ at Maïdo. This implies that we can effectively extract useful information from the obtained partial and total column time series.

\section{Discussion of the retrieval results and comparison with correlative data}

Figure 12 shows the time series of the retrieved total column amounts (in molecules $/ \mathrm{cm}^{2}$ ) of all species observed during the St.-Denis campaigns in 2002 and 2004.

The only reported ground-based measurements of total column abundances in the same latitude belt that we have found to compare our data with, are measurements with a Bruker 120M FTIR spectrometer during a ship cruise across the Atlantic Ocean onboard the German research vessel Polarstern, in October 1996 (Notholt et al., 2000). Our mean total column amounts of $\mathrm{O}_{3}, \mathrm{CH}_{4}, \mathrm{~N}_{2} \mathrm{O}, \mathrm{CO}$, and $\mathrm{C}_{2} \mathrm{H}_{6}$ measured at St.-Denis, being $7.6 \times 10^{18}, 3.6 \times 10^{19}, 6.6 \times 10^{18}$, $1.9 \times 10^{18}$, and $1.1 \times 10^{16}$ molecules $/ \mathrm{cm}^{2}$, respectively, agree well with the average values reported for this cruise between 15 and $20^{\circ} \mathrm{S}$ for $\mathrm{CO}$ and between 20 and $25^{\circ} \mathrm{S}$ for the other gases, namely $6.9 \times 10^{18}, 3.5 \times 10^{19}, 6.4 \times 10^{18}, 2.0 \times 10^{18}$, and $1.0 \times 10^{16}$ molecules $/ \mathrm{cm}^{2}$, respectively.

For $\mathrm{HCl}$ and $\mathrm{HF}$, our total column amounts at Maïdo of $2.8 \times 10^{15}$ and $1.0 \times 10^{15}$ molecules $/ \mathrm{cm}^{2}$, respectively, agree quite well with the values found by long-term FTIR measurements performed at the Northern Hemisphere subtropical site Izaña $\left(28^{\circ} \mathrm{N}, 16^{\circ} \mathrm{W}, 2370 \mathrm{~m}\right.$ a.s.l. $)$ from 1999 to 2003 (Schneider et al., 2005), namely $2.4 \times 10^{15}$ and $0.8 \times 10^{15}$ molecules $/ \mathrm{cm}^{2}$, respectively. The same conclusion can be drawn for the $\mathrm{O}_{3}, \mathrm{~N}_{2} \mathrm{O}$ and $\mathrm{CH}_{4}$ stratospheric columns. Finally, our $\mathrm{HCl}$ total column amounts also agree well with the values found at Mauna Loa $\left(19^{\circ} \mathrm{N}, 156^{\circ} \mathrm{W}\right.$, $3400 \mathrm{~m}$ a.s.1.) by Rinsland et al. (2003), measured with a Bruker 120HR FTIR spectrometer from 1995 to 2001.

The fact that we find almost no data at latitudes around $21^{\circ} \mathrm{S}$ to compare with, demonstrates the importance of performing measurements at Ile de La Réunion.

Because of the limited time periods of the measurement campaigns up to now, we can not clearly distinguish any seasonal variations. Nevertheless, we have observed some interesting short-term variations (Sect. 6.3), we have made differential observations between Maïdo and St.-Denis (Sect. 6.2), and we have performed comparisons with correlative data (Sect. 6.1). 


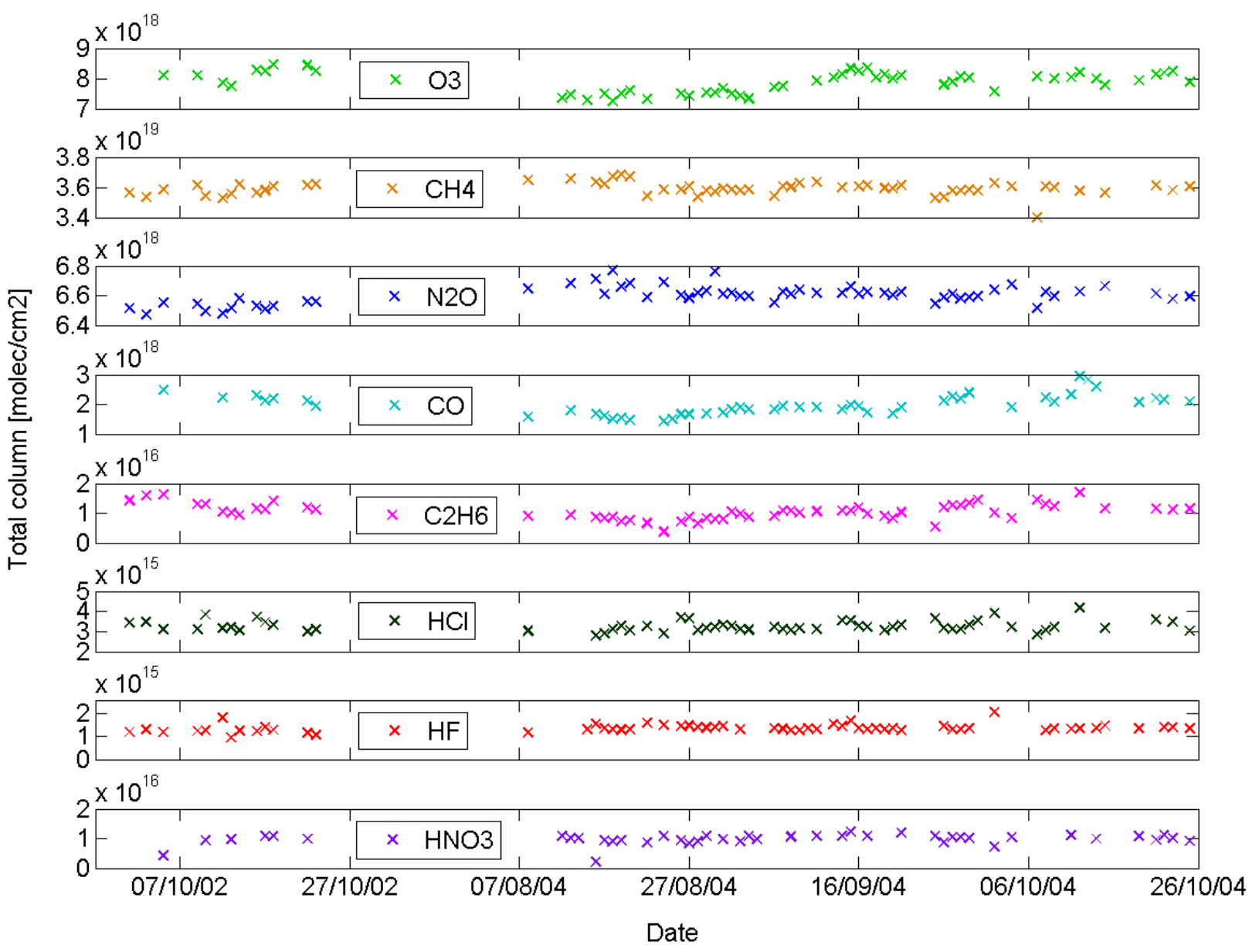

Fig. 12. Time series of the total column amounts (in molecules $/ \mathrm{cm}^{2}$ ) for all retrieved species during the FTIR campaigns at St.-Denis in 2002 and 2004.

\subsection{Comparisons with correlative data}

\subsubsection{Methodology}

The retrieval results obtained from our ground-based FTIR measurements have been compared with correlative vertical profile or partial column data from complementary groundbased observations at the site or from satellites. If the correlative data have a higher vertical resolution than the FTIR data, they are smoothed with the FTIR averaging kernels, using the formula

$\mathbf{x}^{\prime}=\mathbf{x}_{a}+\mathbf{A}\left(\mathbf{x}-\mathbf{x}_{a}\right)$

(Rodgers and Connor, 2003).

For all comparisons with satellite data, we used coincidence criteria of maximum 15 degrees difference in longitude, 10 degrees in latitude, and maximum $24 \mathrm{~h}$ time difference. Besides the comparisons with ACE-FTS data as part of the ACE validation project, we have compared our FTIR observations with validated data from the HALOE satellite instrument. We have not found any other space-borne correlative data to compare with, knowing that MIPAS has stopped operating in nominal mode in March 2004.

In addition to the comparisons with satellite observations, sonde measurements performed at Ile de La Réunion in the frame of the SHADOZ network (http://croc.gsfc.nasa.gov/ shadoz/) are used to evaluate our FTIR data. Unfortunately, there are no correlative $\mathrm{O}_{3}$ profiles available from the lidar instrument at Ile de La Réunion, because the lidar was not operational during our measurement campaigns.

The numerical comparisons between the ground-based FTIR and the correlative data are limited to comparisons between their respective partial columns (PCs) defined by the altitude ranges in which the DOFS is about one. In any case, the comparisons are restricted to the altitude ranges within which the sensitivity of the FTIR measurement, as defined in Sect. 3.3, is equal to or greater than $50 \%$. We therefore define the relative difference between the ground-based FTIR and correlative smoothed sonde or satellite data as 2 $*\left(\mathrm{PC}_{\mathrm{COR}}-\mathrm{PC}_{\mathrm{FTIR}}\right) /\left(\mathrm{PC}_{\mathrm{COR}}+\mathrm{PC}_{\mathrm{FTIR}}\right) * 100$. Note that this definition implies that none of the data is considered as 
Table 5. Relative differences (in $\%$ ) between $\mathrm{O}_{3}$ partial columns from sonde and FTIR measurements at Ile de La Réunion on coincident days. DOFS gives the number of degrees of freedom for the partial column in the high sensitivity altitude range of both instruments. The last column provides the random errors (in \%) on the relative differences, calculated as $4 *\left[\mathrm{PC}_{\text {Sonde }} * \mathrm{PC}_{\mathrm{FTIR}} /\left(\mathrm{PC}_{\text {Sonde }}\right.\right.$ $\left.\left.+\mathrm{PC}_{\mathrm{FTIR}}\right)^{2}\right] * \operatorname{sqrt}\left(\sigma_{\text {Sonde }}^{2}+\sigma_{\mathrm{FTIR}}^{2}\right)$.

\begin{tabular}{lllll}
\hline Date & Altitude range $[\mathrm{km}]$ & DOFS & Rel. diff. [\%] & Error [\%] \\
\hline $18 / 08 / 04$ & $0.05-28.6$ & 3.67 & -0.47 & $\mathbf{2 . 2 2}$ \\
$01 / 09 / 04$ & $0.05-32.2$ & 4.11 & -4.63 & $\mathbf{2 . 0 3}$ \\
$16 / 09 / 04$ & $0.05-31.0$ & 3.78 & -7.77 & $\mathbf{1 . 9 4}$ \\
$04 / 10 / 04$ & $0.05-33.4$ & 4.46 & -4.32 & $\mathbf{2 . 0 2}$ \\
\hline
\end{tabular}

a reference. To support the interpretation of the observed differences between the FTIR and correlative partial column data, we have evaluated the random errors associated with the relative differences, from a combination of the random errors on the FTIR and sonde or satellite partial columns. This combined error is calculated as $4 *\left[\mathrm{PC}_{\mathrm{COR}} * \mathrm{PC}_{\mathrm{FTIR}}\right.$ $\left./\left(\mathrm{PC}_{\mathrm{COR}}+\mathrm{PC}_{\mathrm{FTIR}}\right)^{2}\right] * \operatorname{sqrt}\left(\sigma_{\mathrm{COR}}^{2}+\sigma_{\mathrm{FTIR}}^{2}\right)$, where $\sigma_{\mathrm{COR}}$ and $\sigma_{\text {FTIR }}$ are the relative random errors on the correlative sonde or satellite and on the FTIR partial column, respectively. Note that the smoothing error contribution can be neglected in this evaluation, because we have first smoothed the higher vertical resolution profiles from the sonde or satellite measurements (Rodgers and Connor, 2003).

\subsubsection{Ground-based FTIR versus ozone sonde}

There are only four days during the second campaign on which $\mathrm{O}_{3}$ soundings and FTIR measurements have both been carried out at Ile de La Réunion. These are 18 August, 1 and 16 September, and 4 October 2004. The vertical profiles agree well in the high sensitivity altitude range. As an example, Fig. 13 shows the comparison of the $\mathrm{O}_{3}$ profiles on 16 September 2004. The relative differences (in \%) between the high sensitivity partial columns for all four days are summarized in Table 5, together with the number of DOFS for the partial column in the considered altitude range, and the percentage random errors on the relative differences (as defined in Sect. 6.1.1), from the combined sonde and FTIR random errors. Since the random error budget for the ozone sondes was not given in the NDACC database, we used typical values from the JOSIE-2000 report (Smit and Straeter, 2004): $5 \%$ in every layer from the ground up to $20 \mathrm{~km}$, and $7 \%$ in the layers above. From Table 5, we deduce that the ground-based FTIR retrievals overestimate the amount of $\mathrm{O}_{3}$ between the surface and about $30 \mathrm{~km}$ by 0 to $8 \%$. Of course, this conclusion is based on 4 coincidences only. For all days the combined error is slightly dominated by the sonde errors.

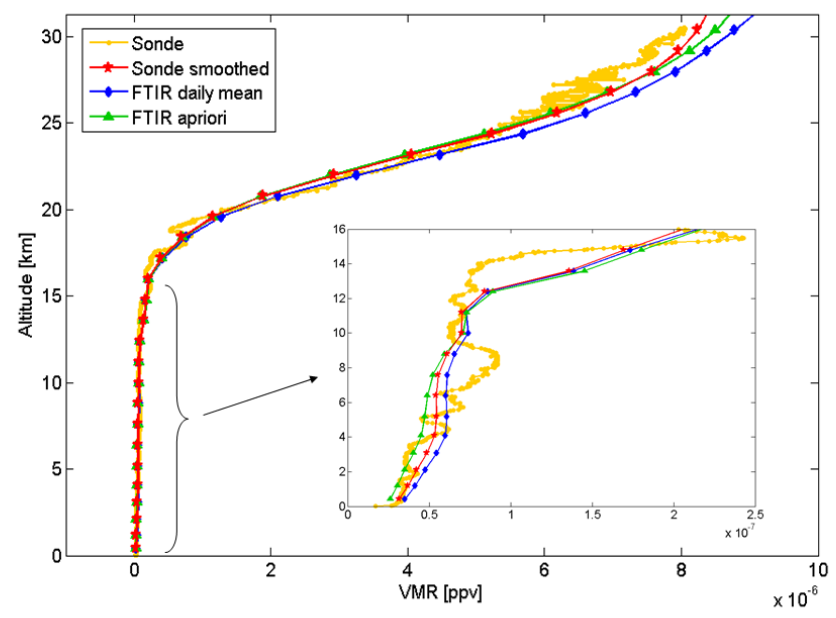

Fig. 13. Comparison of $\mathrm{O}_{3}$ vertical profiles at St.-Denis on 16 September 2004 obtained from ground-based FTIR (blue diamonds) and $\mathrm{O}_{3}$ sonde (yellow dots). Green triangles indicate the a priori FTIR profile and red stars the sonde profile smoothed by the FTIR averaging kernels.

\subsubsection{Ground-based FTIR versus ACE-FTS}

During the 2004 campaign, there have been five overpasses of ACE above Ile de La Réunion: occultation sr5497 on 20 August, occultation ss6153 on 3 October, occultation ss6168 on 4 October, occultation ss6197 on 6 October, and occultation sr6485 on 26 October. For each of these occultations we have compared the ACE-FTS profiles (version v2.2) with our ground-based FTIR data. Note that the profiles measured by the ACE-FTS occultation on October 26 do not reach altitudes below $16.6 \mathrm{~km}$. Therefore the resulting comparisons for that day are not very valuable, but we do include them for completeness.

We have calculated the relative differences between the FTIR and smoothed ACE-FTS partial column amounts of each measured target gas, defined as $2 *\left(\mathrm{PC}_{\mathrm{ACE}}-\mathrm{PC}_{\mathrm{FTIR}}\right)$ $/\left(\mathrm{PC}_{\mathrm{ACE}}+\mathrm{PC}_{\mathrm{FTIR}}\right) * 100$, in the altitude range where both FTIR and ACE-FTS are sensitive.

Figure 14 shows examples of profile comparisons for $\mathrm{CH}_{4}$, $\mathrm{HF}$, and $\mathrm{HNO}_{3}$ on 20 August, for $\mathrm{O}_{3}, \mathrm{~N}_{2} \mathrm{O}, \mathrm{CO}$ and $\mathrm{HCl}$ on 4 October, and for $\mathrm{C}_{2} \mathrm{H}_{6}$ on 6 October. The horizontal red lines indicate the altitude ranges of high sensitivity. Within these ranges the smoothed ACE-FTS profiles agree quite well with the FTIR profiles.

Table 6 lists all comparison results, for each species and each coincident occultation. The above defined relative partial column differences are given (in \%), together with the combined random errors (in \%) on these differences, calculated as $4 *\left[\mathrm{PC}_{\mathrm{ACE}} * \mathrm{PC}_{\mathrm{FTIR}} /\left(\mathrm{PC}_{\mathrm{ACE}}+\mathrm{PC}_{\mathrm{FTIR}}\right)^{2}\right] *$ sqrt $\left(\sigma_{\mathrm{ACE}}^{2}+\sigma_{\mathrm{FTIR}}^{2}\right)$.

In the discussion of the comparisons with the ACE-FTS data we will not take into account the results on 26 October, because of their limited reliability. 
Table 6. Relative differences (in \%) between ACE-FTS and FTIR high sensitivity partial columns at Ile de La Réunion in 2004 for each common measured species, together with the combined random errors, defined as $4 *\left[\mathrm{PC}_{\mathrm{ACE}} * \mathrm{PC}_{\mathrm{FTIR}} /\left(\mathrm{PC}_{\mathrm{ACE}}+\mathrm{PC}_{\mathrm{FTIR}}\right)^{2}\right] * \mathrm{sqrt}$ $\left(\sigma_{\mathrm{ACE}}^{2}+\sigma_{\mathrm{FTIR}}^{2}\right)($ in $\%)$.

\begin{tabular}{|c|c|c|c|c|c|}
\hline Molecule & Date & Altitude range $[\mathrm{km}]$ & DOFS & Rel. diff. [\%] & Error [\%] \\
\hline \multirow[t]{5}{*}{$\mathbf{O}_{3}$} & $20 / 08 / 04$ & $5.8-47.4$ & 4.18 & -3.82 & 0.95 \\
\hline & 03/10/04 & $5.8-47.4$ & 4.33 & 11.11 & 0.86 \\
\hline & $04 / 10 / 04$ & $8.2-47.4$ & 4.08 & 6.36 & 0.84 \\
\hline & $06 / 10 / 04$ & $5.8-36.4$ & 3.46 & -13.34 & 1.25 \\
\hline & $26 / 10 / 04$ & $16.6-47.4$ & 3.19 & -2.83 & 0.90 \\
\hline \multirow{5}{*}{$\mathbf{C H}_{4}$} & $20 / 08 / 04$ & $7.0-28.6$ & 1.35 & -6.16 & 1.40 \\
\hline & 03/10/04 & $5.8-28.6$ & 1.42 & -5.08 & 1.37 \\
\hline & $04 / 10 / 04$ & $8.2-28.6$ & 1.20 & -6.53 & 1.64 \\
\hline & 06/10/04 & $5.8-28.6$ & 1.60 & -0.22 & 1.34 \\
\hline & $26 / 10 / 04$ & $16.6-28.6$ & 0.56 & 2.03 & 11.16 \\
\hline \multirow[t]{5}{*}{$\mathbf{N}_{2} \mathbf{O}$} & $20 / 08 / 04$ & $5.8-25.0$ & 1.75 & -7.42 & 0.59 \\
\hline & 03/10/04 & $5.8-31.0$ & 2.02 & -3.14 & 0.72 \\
\hline & $04 / 10 / 04$ & $8.2-31.0$ & 1.70 & -4.50 & 0.74 \\
\hline & $06 / 10 / 04$ & $5.8-28.6$ & 6.57 & 15.03 & 0.73 \\
\hline & $26 / 10 / 04$ & $16.6-25.0$ & 0.70 & 12.36 & 1.45 \\
\hline \multirow[t]{4}{*}{$\mathrm{CO}$} & $20 / 08 / 04$ & $7.0-19.0$ & 1.19 & -18.80 & 3.33 \\
\hline & $03 / 10 / 04$ & $5.8-19.0$ & 1.31 & 25.02 & 3.49 \\
\hline & $04 / 10 / 04$ & $8.2-19.0$ & 0.96 & -17.82 & 3.27 \\
\hline & $26 / 10 / 04$ & $16.6-20.2$ & 0.10 & -2.44 & 3.57 \\
\hline \multirow[t]{5}{*}{$\mathbf{C}_{2} \mathbf{H}_{6}$} & $20 / 08 / 04$ & $8.2-20.2$ & 0.88 & -14.15 & 8.94 \\
\hline & $03 / 10 / 04$ & $7.0-20.2$ & 1.24 & 25.27 & 6.16 \\
\hline & $04 / 10 / 04$ & $8.2-20.2$ & 1.16 & -37.19 & 7.08 \\
\hline & $06 / 10 / 04$ & $7.0-19.0$ & 0.78 & -39.02 & 12.98 \\
\hline & $26 / 10 / 04$ & $17.8-20.2$ & 0.09 & -47.75 & 19.22 \\
\hline \multirow{5}{*}{$\mathrm{HCl}$} & $20 / 08 / 04$ & $8.2-47.4$ & 1.38 & 10.16 & 4.10 \\
\hline & $03 / 10 / 04$ & $9.4-42.4$ & 1.28 & 30.31 & 3.37 \\
\hline & $04 / 10 / 04$ & $9.4-42.4$ & 1.28 & 15.08 & 3.41 \\
\hline & $06 / 10 / 04$ & $8.2-47.4$ & 1.25 & -8.24 & 4.32 \\
\hline & $26 / 10 / 04$ & $16.6-44.8$ & 1.07 & -22.73 & 2.58 \\
\hline \multirow[t]{2}{*}{ HF } & $20 / 08 / 04$ & $14.2-40.2$ & 1.14 & -3.41 & 3.12 \\
\hline & $26 / 10 / 04$ & $17.8-38.2$ & 1.07 & -47.65 & 2.48 \\
\hline \multirow[t]{5}{*}{$\mathrm{HNO}_{3}$} & $20 / 08 / 04$ & $16.6-32.2$ & 0.93 & 3.41 & 4.67 \\
\hline & 03/10/04 & $16.6-28.6$ & 1.09 & 25.93 & 4.73 \\
\hline & $04 / 10 / 04$ & $16.6-28.6$ & 1.09 & 5.59 & 4.80 \\
\hline & $06 / 10 / 04$ & $16.6-32.2$ & 1.03 & -30.89 & 4.59 \\
\hline & $26 / 10 / 04$ & $16.6-28.6$ & 0.97 & -49.62 & 4.05 \\
\hline
\end{tabular}

For $\mathrm{O}_{3}$, the relative differences between ACE-FTS and ground-based FTIR vary between -14 and $+12 \%$, in the middle troposphere $(\sim 6 \mathrm{~km})$ up to the stratopause $(\sim 47 \mathrm{~km})$. For $\mathrm{CH}_{4}$ and $\mathrm{N}_{2} \mathrm{O}$, the relative differences between ACE-FTS and ground-based FTIR range from -7 to $0 \%$ and from -8 to $+15 \%$, respectively, in the middle troposphere up to about $30 \mathrm{~km}$. For $\mathrm{CO}$ and $\mathrm{C}_{2} \mathrm{H}_{6}$, the upper altitude limit for the comparison is restricted to $20 \mathrm{~km}$; the differences between ACE-FTS and ground-based FTIR vary between -19 and $+25 \%$ for $\mathrm{CO}$, and between -39 and $+26 \%$ for $\mathrm{C}_{2} \mathrm{H}_{6}$. The altitude range for the comparison of $\mathrm{HCl}$ goes from the middle troposphere to about the stratopause; the observed differences range from -9 to $+31 \%$.
For HF, we have only one reliable comparison, namely on 20 August, for which the relative difference between the ACE-FTS and the ground-based FTIR partial column in the range 14 to $40 \mathrm{~km}$ is about $-4 \%$. Comparisons for $\mathrm{HNO}_{3}$ in the range 17 to $30 \mathrm{~km}$, show differences between -31 and $+26 \%$.

In all mentioned comparisons, the variations in the observed differences are larger than what we expect on the basis of the random errors on the relative differences. For all species we see that the FTIR errors are equivalent to or slightly bigger than the ACE-FTS errors. 
Table 7. Relative differences (in \%) between HALOE and FTIR high sensitivity partial columns at Ile de La Réunion in 2004 for each common measured species, together with the combined random error, defined as $4 *\left[\mathrm{PC}_{\mathrm{HALOE}} * \mathrm{PC}_{\mathrm{FTIR}} /\left(\mathrm{PC}_{\mathrm{HALOE}}+\mathrm{PC}_{\mathrm{FTIR}}\right)^{2}\right] * \mathrm{sqrt}$ $\left(\sigma_{\mathrm{HALOE}}^{2}+\sigma_{\mathrm{FTIR}}^{2}\right)($ in $\%)$.

\begin{tabular}{lrrrrr}
\hline Molecule & Date & Altitude range [km] & DOFS & Rel. diff. [\%] & Error [\%] \\
\hline $\mathbf{O}_{3}$ & $29 / 08 / 04$ & $10.6-47.4$ & 3.66 & -12.34 & $\mathbf{1 . 6 4}$ \\
& $30 / 08 / 04$ & $10.6-47.4$ & 3.54 & -9.03 & $\mathbf{0 . 8 9}$ \\
& $31 / 08 / 04$ & $10.6-50.8$ & 3.61 & -14.82 & $\mathbf{0 . 9 2}$ \\
& $14 / 09 / 04$ & $10.6-42.4$ & 3.32 & -56.51 & $\mathbf{1 6 . 3 0}$ \\
& $15 / 09 / 04$ & $10.6-50.8$ & 3.63 & -13.09 & $\mathbf{0 . 9 0}$ \\
$\mathbf{C H}_{4}$ & $16 / 09 / 04$ & $10.6-47.4$ & 3.46 & -16.31 & $\mathbf{0 . 8 7}$ \\
& $29 / 08 / 04$ & $14.2-28.6$ & 0.71 & -6.86 & $\mathbf{1 0 . 7 1}$ \\
& $30 / 08 / 04$ & $14.2-28.6$ & 0.70 & -8.47 & $\mathbf{5 . 2 6}$ \\
& $31 / 08 / 04$ & $14.2-28.6$ & 0.70 & -5.22 & $\mathbf{5 . 3 7}$ \\
$\mathbf{H C l}$ & $14 / 09 / 04$ & $14.2-28.6$ & 0.69 & -4.76 & $\mathbf{5 . 3 4}$ \\
& $15 / 09 / 04$ & $14.2-28.6$ & 0.69 & -5.57 & $\mathbf{7 . 9 7}$ \\
& $16 / 09 / 04$ & $14.2-28.6$ & 0.72 & -4.67 & $\mathbf{5 . 4 4}$ \\
& $29 / 08 / 04$ & $15.4-44.8$ & 1.09 & 2.13 & $\mathbf{1 3 . 9 4}$ \\
& $30 / 08 / 04$ & $15.4-44.8$ & 1.00 & -7.86 & $\mathbf{8 . 8 7}$ \\
& $31 / 08 / 04$ & $15.4-23.8$ & 1.91 & -15.24 & $\mathbf{1 1 . 1 3}$ \\
& $14 / 09 / 04$ & $15.4-44.8$ & 1.20 & -47.09 & $\mathbf{1 . 9 4}$ \\
& $15 / 09 / 04$ & $16.6-47.4$ & 0.74 & -15.51 & $\mathbf{2 . 8 7}$ \\
& $16 / 09 / 04$ & $15.4-44.8$ & 1.51 & 2.04 & $\mathbf{2 . 1 4}$ \\
& $29 / 08 / 04$ & $15.4-40.2$ & 1.15 & -0.10 & $\mathbf{8 . 5 7}$ \\
& $30 / 08 / 04$ & $15.4-40.2$ & 1.18 & -8.30 & $\mathbf{2 . 9 7}$ \\
& $31 / 08 / 04$ & $15.4-40.2$ & 1.17 & -13.59 & $\mathbf{3 . 9 1}$ \\
& $14 / 09 / 04$ & $15.4-40.2$ & 1.13 & -45.44 & $\mathbf{4 . 8 0}$ \\
& $15 / 09 / 04$ & $15.4-38.2$ & 1.11 & -19.25 & $\mathbf{2 . 7 3}$ \\
& $16 / 09 / 04$ & $15.4-38.2$ & 1.10 & -1.06 & $\mathbf{4 . 3 6}$ \\
\hline \multirow{6}{*}{ HF } & & & & &
\end{tabular}

\subsubsection{Ground-based FTIR versus HALOE}

In the same way as we did for ACE-FTS, we have compared our ground-based FTIR data with correlative data from HALOE. Conform to the ACE comparisons in this paper, we have calculated the relative differences between the FTIR and smoothed HALOE partial column amounts as $2 *$ $\left(\mathrm{PC}_{\mathrm{HALOE}}-\mathrm{PC}_{\mathrm{FTIR}}\right) /\left(\mathrm{PC}_{\mathrm{HALOE}}+\mathrm{PC}_{\mathrm{FTIR}}\right) * 100$, in the altitude range where both FTIR and HALOE are sensitive for the target species.

Figure 15 shows examples of comparisons between retrieved FTIR and the original and smoothed HALOE profiles of $\mathrm{O}_{3}, \mathrm{CH}_{4}, \mathrm{HCl}$, and $\mathrm{HF}$ on 16 September 2004. The horizontal red lines indicate the altitude ranges of high sensitivity. Analogue to the ACE-FTS comparisons, the smoothed HALOE profiles agree fairly well with the FTIR profiles within these ranges. Table 7 gives an overview of all comparisons, for each species and each coincident occultation. The relative differences on the relevant partial column are given (in \%), together with the associated DOFS and random error (in \%), defined as $4 *\left[\mathrm{PC}_{\mathrm{HALOE}} * \mathrm{PC}_{\mathrm{FTIR}} /\left(\mathrm{PC}_{\mathrm{HALOE}}+\right.\right.$ $\left.\left.\mathrm{PC}_{\mathrm{FTIR}}\right)^{2}\right] * \operatorname{sqrt}\left(\sigma_{\mathrm{HALOE}}^{2}+\sigma_{\mathrm{FTIR}}^{2}\right)$. It appears in Table 7 that the discrepancies between HALOE and ground-based FTIR partial columns are always larger on 14 September 2004 than on the other days. We have verified the HALOE and ground- based FTIR data for that particular day and up to now, we haven't found any good explanation for the large inconsistencies. We therefore don't take into account that day in the current discussion.

For $\mathrm{HCl}$ and $\mathrm{HF}$, in general, the HALOE partial columns in the range 15 to $45 \mathrm{~km}$ and 15 to $40 \mathrm{~km}$, respectively, are smaller than the corresponding FTIR partial columns, by about 7 to $16 \%$ and 1 to $20 \%$, respectively. This agrees to some extent with previous findings by Russell et al. (1996a, 1996b) saying that HALOE slightly underestimates the $\mathrm{HCl}$ and HF vmr profiles. In particular, they found that the mean difference between HALOE and correlative balloon measurements is better than $7 \%$ for $\mathrm{HF}$ and ranges from 8 to $19 \%$ for $\mathrm{HCl}$, throughout most of the stratosphere. Following Russell et al. there appears to be a systematic offset between HALOE and ATMOS measurements ranging from 10 to $20 \%$ both for $\mathrm{HF}$ and $\mathrm{HCl}$, and even reaching $40 \%$ for $\mathrm{HF}$ in the lower stratosphere. The differences between the HALOE and ground-based FTIR $\mathrm{O}_{3}$ partial columns in the range 10 to $47 \mathrm{~km}$ vary between 9 and $17 \%$, with the HALOE profiles being smaller than the ground-based FTIR profiles. For $\mathrm{CH}_{4}$, the HALOE partial columns in the lower stratosphere (15 to $28 \mathrm{~km}$ ) are smaller than the ground-based FTIR columns by about 4 to $9 \%$. 

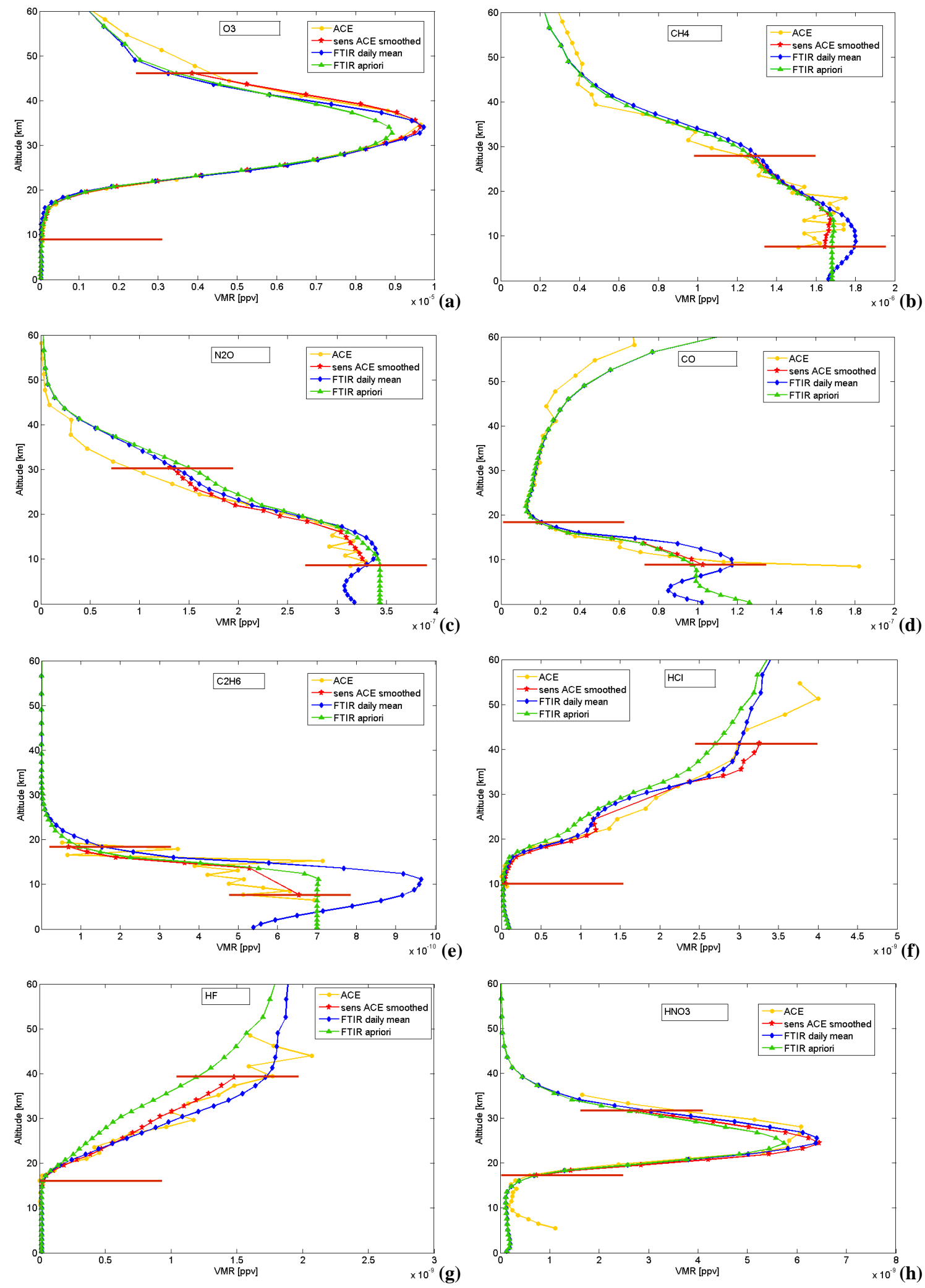

Fig. 14. Vertical vmr profiles from 0 to $60 \mathrm{~km}$ of (a) $\mathrm{O}_{3}$ on 4 October, (b) $\mathrm{CH}_{4}$ on 20 August, (c) $\mathrm{N}_{2} \mathrm{O}$ on 4 October, (d) $\mathrm{CO}$ on 4 October, (e) $\mathrm{C}_{2} \mathrm{H}_{6}$ on 6 October, (f) $\mathrm{HCl}$ on 4 October, (g) HF on 20 August, and (h) $\mathrm{HNO}_{3}$ on 20 August, measured at St.-Denis in 2004 by groundbased FTIR (blue diamonds) and by ACE-FTS (raw: yellow circles; smoothed: red stars). The FTIR a priori profile is indicated by the green triangles. 

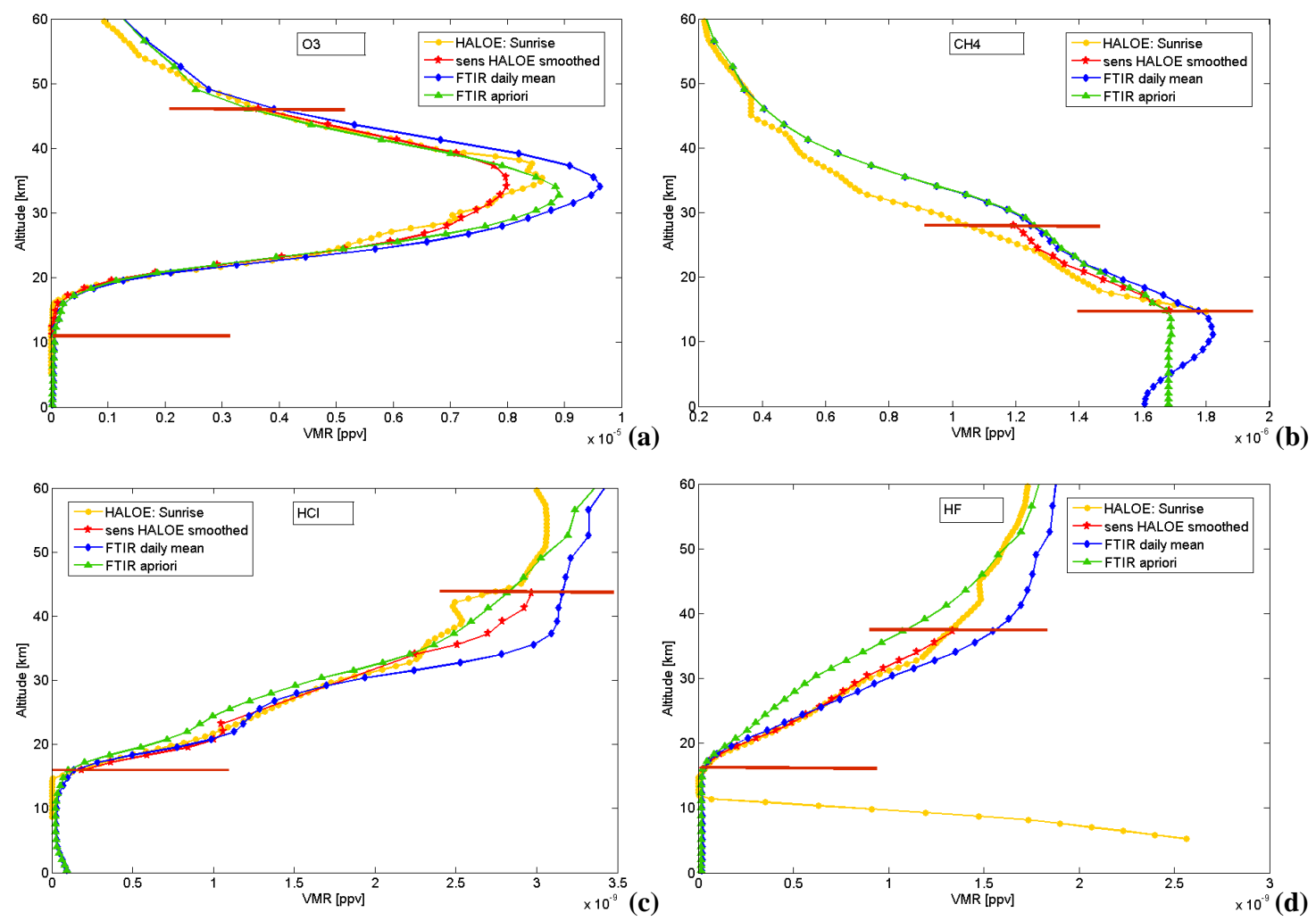

Fig. 15. Vertical vmr profiles form 0 to $60 \mathrm{~km}$ of (a) $\mathrm{O}_{3}$, (b) $\mathrm{CH}_{4}$, (c) $\mathrm{HCl}$ and (d) HF, measured at St.-Denis by ground-based FTIR (blue diamonds) and by HALOE (raw: yellow circles; smoothed: red stars) on 16 September 2004. The green triangles indicate the a priori FTIR profile.

For $\mathrm{O}_{3}$ and $\mathrm{CH}_{4}$ the combined error is dominated by the FTIR errors, whereas for $\mathrm{HCl}$ and $\mathrm{HF}$ it is dominated by the HALOE errors.

\subsection{Differential observations between Maïdo and St.-Denis}

The campaign in 2002 has allowed us to look at the species' abundances in the about $2.15 \mathrm{~km}$ thick atmospheric bottom layer between St.-Denis and Maïdo. Unfortunately, only very few measurements could be made on exactly the same day at both sites, because of meteorological conditions.

Figure 16 shows the total column amounts (TC) of $\mathrm{O}_{3}$, $\mathrm{CH}_{4}, \mathrm{~N}_{2} \mathrm{O}, \mathrm{CO}, \mathrm{C}_{2} \mathrm{H}_{6}, \mathrm{HCl}, \mathrm{HF}$, and $\mathrm{HNO}_{3}$, retrieved at Maïdo and at St.-Denis in 2002, together with their respective absolute differences, $\mathrm{TC}_{\text {StDenis }}-\mathrm{TC}_{\text {Maido }}$, and the combined random error on those differences, defined as sqrt $\left(\sigma_{\mathrm{StDenis}}^{2} *\right.$ $\mathrm{TC}_{\text {StDenis }}^{2}+\sigma_{\text {Maido }}^{2} * \mathrm{TC}_{\text {Maido }}^{2}$ ), where $\sigma_{\text {StDenis }}$ and $\sigma_{\text {Maido }}$ are the relative random error on the total columns at St.-Denis and Maïdo, respectively.

As expected, the total column amounts measured on the same day at both sites coincide within the error bars for the stratospheric species $\mathrm{HCl}, \mathrm{HF}$ and $\mathrm{HNO}_{3}$. For the tropospheric species $\mathrm{CH}_{4}, \mathrm{~N}_{2} \mathrm{O}, \mathrm{CO}$, and $\mathrm{C}_{2} \mathrm{H}_{6}$ there is a significant offset in their total columns, corresponding to their abundances in the atmospheric layer in between both obser- vatories. For $\mathrm{O}_{3}$, there is also a small offset, confirming its non-zero concentration in the boundary layer.

Based on these differences between the column values at Maïdo and at St.-Denis, we can derive an estimate of the surface volume mixing ratios of the target species, assuming a constant vmr between 0.05 and $2.2 \mathrm{~km}$. This is a good assumption for the well-mixed long-lived gases $\mathrm{CH}_{4}$ and $\mathrm{N}_{2} \mathrm{O}$, and a reasonable approximation for the other ones. Our thus obtained estimates are $1324 \mathrm{ppbv}$ for $\mathrm{CH}_{4}, 86 \mathrm{ppbv}$ for $\mathrm{CO}$, 265 ppbv for $\mathrm{N}_{2} \mathrm{O}$, and 139 pptv for $\mathrm{C}_{2} \mathrm{H}_{6}$.

For $\mathrm{CH}_{4}$ and $\mathrm{CO}$ the values agree well (i.e., within the error bars) with the ones from the NOAA ESRL Globalview database (http://www.esrl.noaa.gov/gmd/ccgg/globalview/ co/co_intro.html), namely about 1750 and $80 \mathrm{ppbv}$, respectively, at $20^{\circ} \mathrm{S}$ in October, if we take into account the total uncertainties on the total column values, including the systematic uncertainties. Analogously, our estimate of the $\mathrm{N}_{2} \mathrm{O}$ surface concentration agrees reasonably well with the value of $316 \mathrm{ppbv}$ at the Southern Hemisphere station of Cape Matatula $\left(14^{\circ} \mathrm{S}, 171^{\circ} \mathrm{W}\right)$ in 2002 , reported by Jiang et al. (2007). 

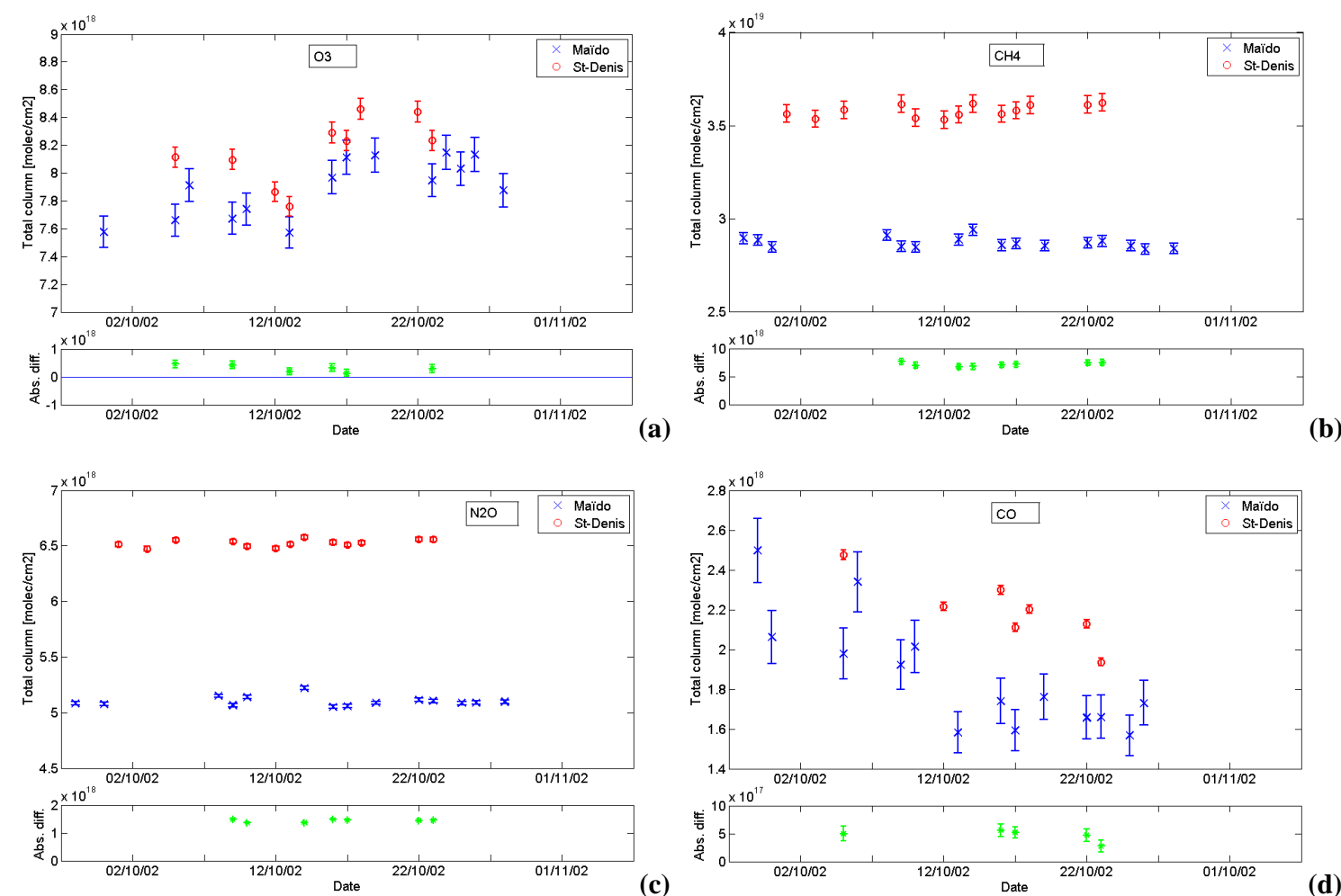

(d)
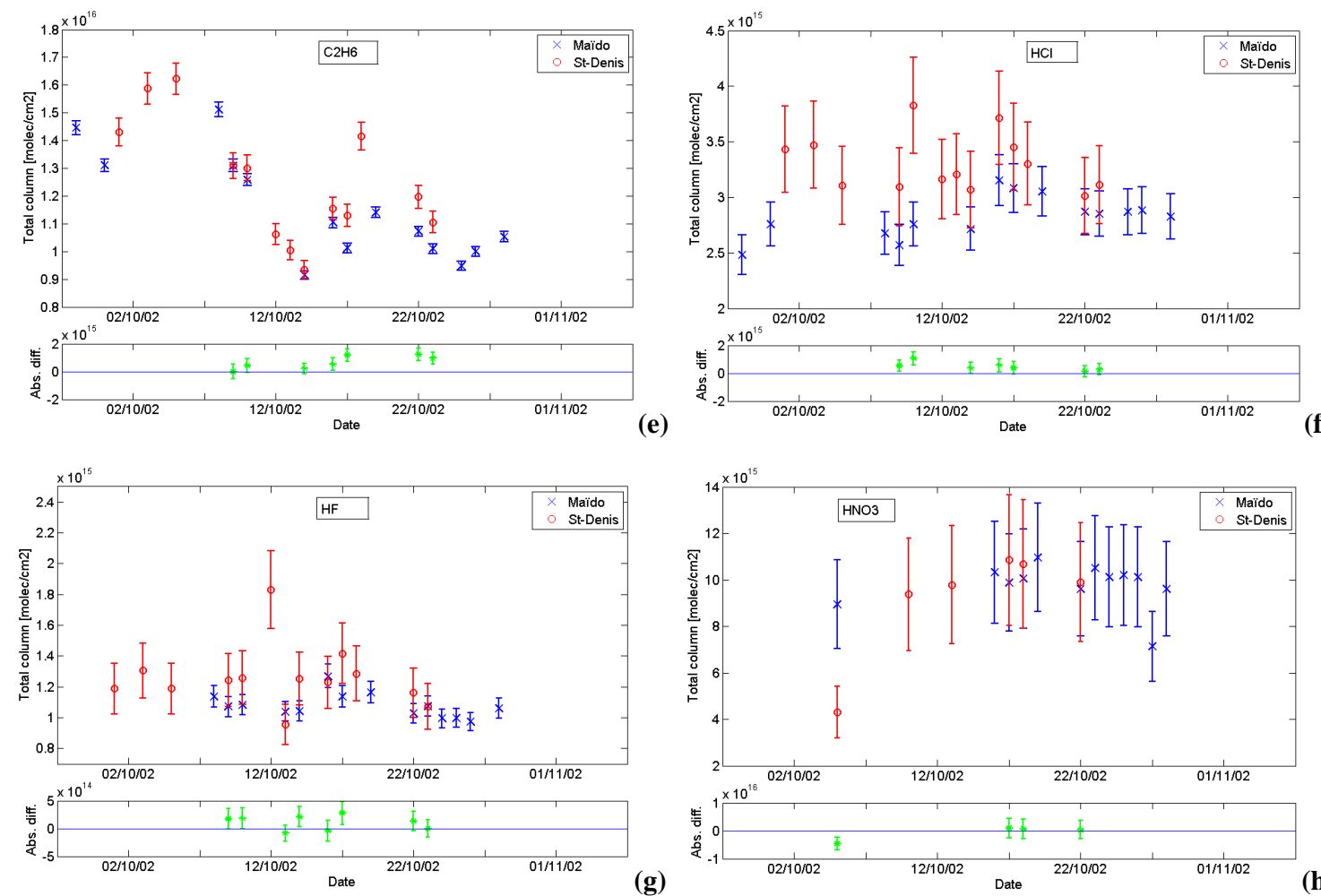

(h)

Fig. 16. Upper plots: total column amounts (in molecules/ $/ \mathrm{cm}^{2}$ ) together with random error bars of (a) $\mathrm{O}_{3}$, (b) $\mathrm{CH}_{4}$, (c) $\mathrm{N}_{2} \mathrm{O}$, (d) $\mathrm{CO}$, (e) $\mathrm{C}_{2} \mathrm{H}_{6}$, (f) $\mathrm{HCl}$, (g) $\mathrm{HF}$, and (h) $\mathrm{HNO}_{3}$, measured at Maïdo (blue crosses) and at St.-Denis (red circles) in 2002 by ground-based FTIR. Lower plots: absolute differences (in molecules $/ \mathrm{cm}^{2}$ ) of the total column amounts, calculated as the St.-Denis column value minus the Maïdo one, together with their random error bars. 

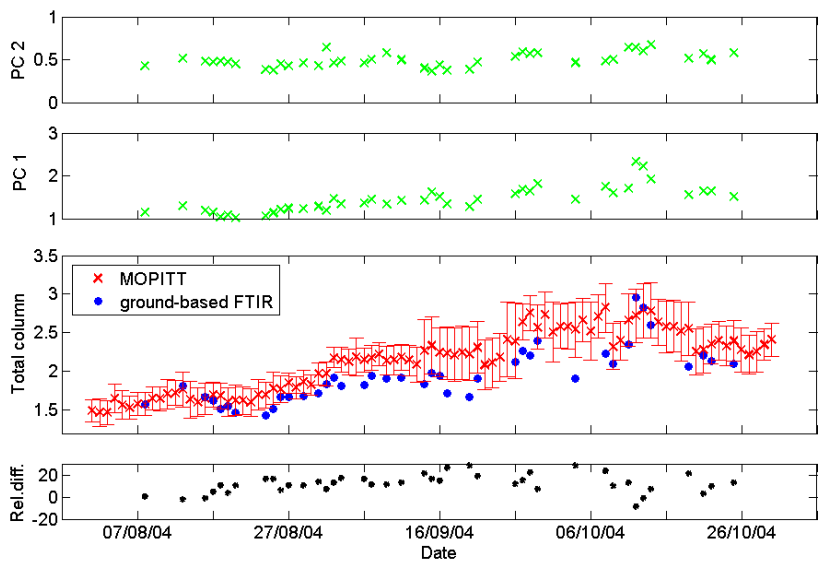

Fig. 17. From top to bottom: Time series from the period August-October 2004 of daily mean CO abundances (in $10^{18}$ molecules $/ \mathrm{cm}^{2}$ ) measured by the ground-based FTIR instrument at St.-Denis, in the $9.4-100 \mathrm{~km}$ layer (PC2), in the surface to $9.4 \mathrm{~km}$ layer (PC1), and in the total column (blue circles). The latter plot also includes the daily mean CO total column amounts and associated standard deviations measured by MOPITT (red crosses). The lowest plot shows the relative differences (in \%) between the MOPITT and ground-based FTIR data for the CO total columns, on coincident days.

6.3 Impact of biomass burning emissions on $\mathrm{CO}$ and $\mathrm{C}_{2} \mathrm{H}_{6}$ abundances

6.3.1 CO total columns from ground-based FTIR compared to MOPITT

We compared the retrieved $\mathrm{CO}$ total columns with data from the MOPITT instrument.

Figure 17 shows the $\mathrm{CO}$ partial and total columns above Ile de La Réunion obtained from our ground-based FTIR measurements during the campaign in 2004, together with the correlative total columns from MOPITT. It also includes the relative differences between both data sets for coinciding dates, defined as $2 *\left(\mathrm{TC}_{\text {MOPITT }}-\mathrm{TC}_{\mathrm{FTIR}}\right) /\left(\mathrm{TC}_{\text {MOPITT }}\right.$ $\left.+\mathrm{TC}_{\mathrm{FTIR}}\right) * 100$. We observe a very good agreement between the time series, both showing the seasonal trend of $\mathrm{CO}$ - although MOPITT seems to slightly overestimate the CO concentrations - and an additional increase around 12 October. The mean relative difference between the corresponding FTIR and MOPITT total column values is $11.9 \%$. A similar bias was also noticed by Barret et al. (2003) and Emmons et al. (2004).

\subsubsection{Transport of biomass burning pollutants}

The observed rise of the $\mathrm{CO}$ tropospheric concentrations by the end of October 2004 agrees with the known seasonal cycle of $\mathrm{CO}$ in the southern tropical and subtropical regions, which is attributed to the effect of enhanced mean biomass burning and cross-equatorial transport of $\mathrm{CO}$ from the North- ern Hemisphere (WMO WDCGG, 2006). We have been able to verify that the additional increase for a few days around 12 October takes place in the (lower) troposphere (see also Fig. 17) and that it originates from fire emissions in Southern Africa and Madagascar. In order to establish a clear sourcereceptor relationship between the FTIR site at St.-Denis and potential gas emitting locations, we calculated retroplumes using the Lagrangian particle dispersion model FLEXPART, version 6.2 (Stohl et al., 1998, 2005). This model simulates the transport and dispersion of linear tracers, by calculating the trajectories of a chosen ensemble of particles. Not only do the retroplumes trace the origin of a particular air mass, they also give an estimate on the amount of time the air mass has spent in close proximity to the Earth's surface. Knowledge of this residence time delivers insight into the ratio of the emitted to detected trace gas. The FLEXPART model was driven by global wind field data from ECMWF, with a spatial resolution of $1^{\circ} \times 1^{\circ}$ and 60 vertical levels and a temporal resolution of $3 \mathrm{~h}$. The fire emissions used are 8 day averages taken from the Global Fire Emissions Database (GFED), version 2 (Van der Werf et al., 2006), using MODIS fire hot spots (Giglio et al., 2003). The emissions were distributed as follows: $20 \%$ between $0-100 \mathrm{~m}$ altitude, $40 \%$ between $100-500 \mathrm{~m}$ and $40 \%$ between $500-1000 \mathrm{~m}$. Anthropogenic $\mathrm{CO}$ emissions, which have a small contribution, were taken from the EDGAR 3.2 Fast Track 2000 database (http://www.mnp.nl/edgar). Background $\mathrm{CO}$ was fixed at $85 \mathrm{ppb}$, since this is the lowest $\mathrm{CO}$ amount between 1 and $13 \mathrm{~km}$, observed by FTIR in the period September-October, 2004. Note that this could well be an underestimation, as background $\mathrm{CO}$ levels are increasing in this period. For our calculations we released 200000 particles between 0 and $13 \mathrm{~km}$ over St.-Denis for each corresponding FTIR measurement. Each release lasted for $602 \mathrm{~s}$ and each CO retroplume was traced back in time for 20 days. For each retroplume, its residence time near the surface has been calculated (in $\mathrm{s} \mathrm{m}^{3} \mathrm{~kg}^{-1}$ ). If this response function is folded with the 3-D field of emission flux data (in $\mathrm{kg} \mathrm{m}^{-3} \mathrm{~s}^{-1}$ ) into this grid box, a mass mixing ratio at the receptor point is obtained. Figure 18 shows a comparison of time series of $\mathrm{CO}$ abundances between 0 and $13 \mathrm{~km}$ altitude at Ile de La Réunion in October 2004, measured by ground-based FTIR and calculated by FLEXPART. One can clearly see an enhancement in the CO amounts around 12 October, although much more obvious in the FTIR time series than in the FLEXPART series. This increase can be attributed to the transport of $\mathrm{CO}$ amounts originating from biomass burning events in Madagascar and Southern Africa the days before, as confirmed by Fig. 19, showing the total $\mathrm{CO}$ amounts emitted and transported to Ile de La Réunion on 12 October.

In order to obtain in the FLEXPART simulations the same $\mathrm{CO}$ levels as the observed ones, we had to increase the GFED emissions by a factor of 4 ; the corresponding time series are also shown in Fig. 18. One must not forget however that there are quite some uncertainties in the fire emissions due to 


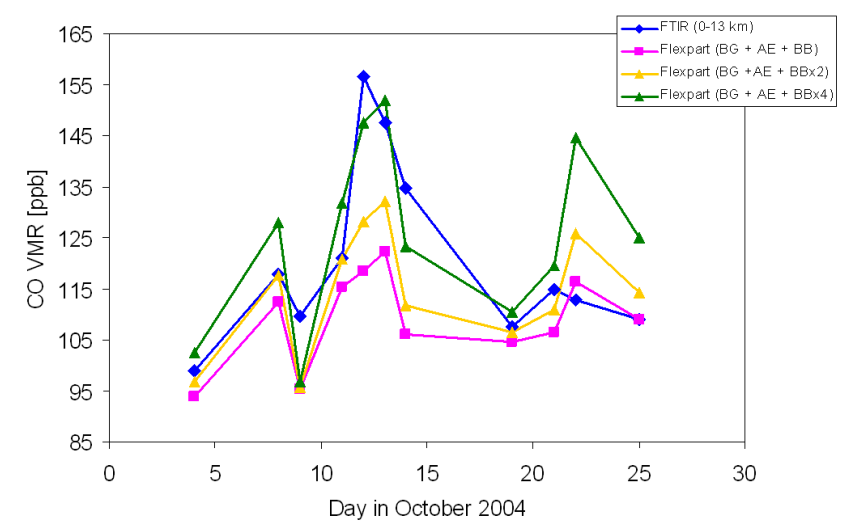

Fig. 18. Time series of $\mathrm{CO}$ abundances at St.-Denis between 0 and $13 \mathrm{~km}$, in October 2004, calculated by ground-based FTIR (blue diamonds) and FLEXPART with (1) GFED emissions (pink squares), (2) GFED emissions x 2 (yellow triangles), and (3) GFED emissions x 4 (green triangles).

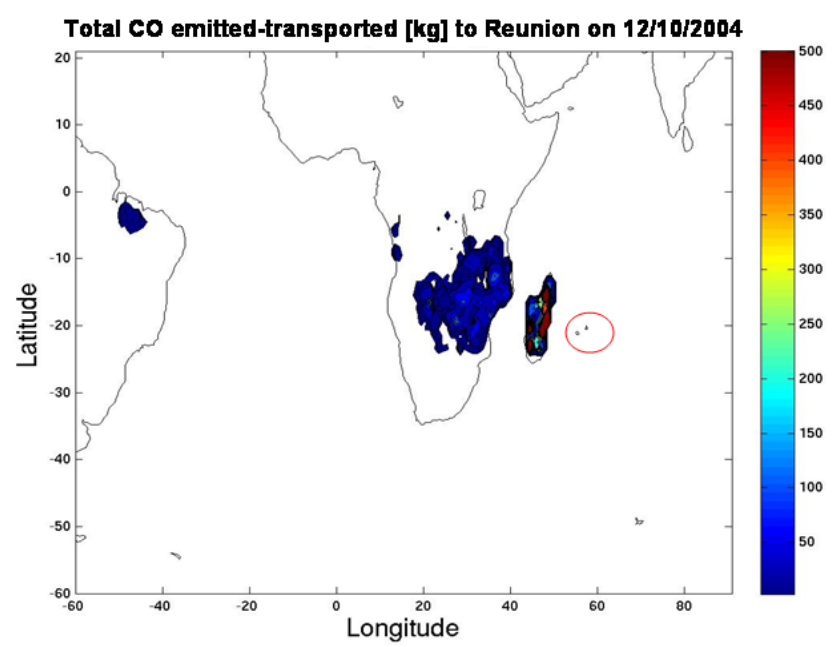

Fig. 19. Total amount of CO emitted and transported (in $\mathrm{kg}$ ) to Ile de La Réunion (located within the red circle) on 12 October 2004, calculated by FLEXPART.

their high variability. Other factors that could lead to the observed differences between the FLEXPART simulations and the ground-based FTIR observations are: (1) we have traced back the emissions to 20 days, while the lifetime of $\mathrm{CO}$ permits contributions from larger time frames, (2) there are still non negligible errors in the wind fields, especially in their vertical component, (3) the temporal emission resolution (8 day averages) is not very accurate, and (4) the choice of the vertical distribution of the emissions up to $1 \mathrm{~km}$ is rather arbitrary since in reality the altitude dependence of the emissions is strongly influenced by the size, temperature, and type of fire (e.g., Hyer et al., 2007).

Rinsland et al. (1998) and Zhao et al. (2002) have shown that $\mathrm{CO}$ enhancements originating in biomass burning are

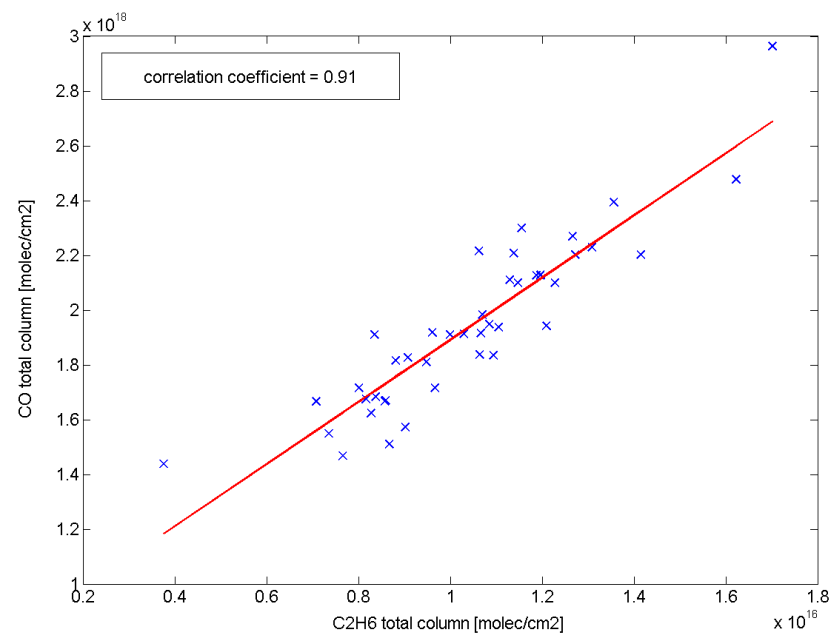

Fig. 20. Correlation plot $(n=42)$ of $\mathrm{CO}$ versus $\mathrm{C}_{2} \mathrm{H}_{6}$ total column amounts (in molecules $/ \mathrm{cm}^{2}$ ) during the FTIR campaigns at St.-Denis in 2002 and 2004.

strongly correlated with enhancements in $\mathrm{C}_{2} \mathrm{H}_{6}$. Such correlation has indeed been observed in our data sets: the time series of the total column values of $\mathrm{C}_{2} \mathrm{H}_{6}$ at St.-Denis in 2004 shows an increase by the end of October, in line with the observed increase of the tropospheric CO amount (Fig. 17). This is even better seen in Fig. 20 that shows the correlation plot of $\mathrm{CO}$ total columns versus $\mathrm{C}_{2} \mathrm{H}_{6}$ total columns during the 2002 and 2004 campaigns at St.-Denis. The correlation coefficient equals 0.91 (number of points is 42), confirming that the observed increases have the same origin, namely tropical biomass burning in Madagascar and on the African continent.

\section{Conclusions and perspectives}

Ground-based FTIR spectroscopy is a very useful technique to derive total column abundances and low-resolution vertical profiles of many important trace gases in the atmosphere. The technique is being used at many stations worldwide, mostly in the frame of NDACC, but rarely at low-altitude tropical or subtropical stations. Up to now, there are no regular FTIR measurements in the southern tropics.

In this technical note, we have reported the first two FTIR measurement campaigns at Ile de La Réunion, located at $21^{\circ} \mathrm{S}$ and $55^{\circ} \mathrm{E}$, in the southern (sub)tropics. The first measurement campaign in 2002 included observations from a low- and high-altitude site simultaneously. The second campaign was performed at the low-altitude site St.-Denis only.

We have demonstrated the feasibility of these observations, at both sites, including a full error budget evaluation. Our results show that we can derive total column amounts and some vertical profile information for many of the atmospheric species of interest in tropospheric and strato- 
spheric chemistry, with a precision that allows the detection of atmospheric variability. We also show that the capabilities at the high-altitude site are better than at sea level, but that it is nevertheless possible to also obtain useful data at the lowaltitude site, even if water vapour causes significant interfering absorptions in the spectra. The error due to interfering species is the dominant random error source for the retrieval of $\mathrm{C}_{2} \mathrm{H}_{6}$ at St.-Denis; for all other species, other sources of error are more important. In particular, we have shown that we obtain between 1 and 5 independent pieces of information, depending on the species. This allowed us to retrieve partial column abundances for $\mathrm{O}_{3}, \mathrm{CH}_{4}, \mathrm{~N}_{2} \mathrm{O}$ and $\mathrm{CO}$ and total column values for $\mathrm{HF}, \mathrm{HCl}, \mathrm{HNO}_{3}$ and $\mathrm{C}_{2} \mathrm{H}_{6}$. We have verified our data by comparisons with correlative data from satellite or sonde, and with literature values.

From the differential measurements performed during the first campaign, we have retrieved valid boundary layer information for the tropospheric species. The shortness of the campaign has prohibited investigation of the variability in the boundary layer.

It is known that the Southern Hemisphere troposphere is affected by biomass burning emissions in the dry season (September-November), which explains part of the observed variation for species like $\mathrm{CO}$ and $\mathrm{C}_{2} \mathrm{H}_{6}$. Here, we have confirmed that the chemical composition of the troposphere above Ile de La Réunion can suffer significant impacts from biomass burning emission events in Africa and Madagascar. Such an event was investigated in local spring 2004, supported by FLEXPART simulations.

It is planned to continue this type of measurements, first on a campaign basis and in the future on a permanent basis, and to retrieve additional species of interest, e.g., for the characterization of biomass burning emissions and transport.

A third campaign has been held in 2007, lasting from May until the end of October; the data will be used for the validation of IASI onboard METOP-1. A new campaign is planned for end of 2008 to 2009. From 2010 onward, we will be able to operate a Bruker 125HR instrument at the new NDACC infrastructure at the Maïdo: this experiment will enable regular high-quality ground-based FTIR measurements from this complementary NDACC site. The measurements will contribute to the NDACC database and further support satellite and model validation in the tropics where ground-based data are highly needed. As the dataset grows, it will provide useful information to studies of atmospheric processes in the southern (sub)tropics.

Acknowledgements. Thanks for financial support for the campaigns at Ile de La Réunion and associated research are due to the Belgian Federal Science Policy (Ministerial Order MO/35/020, ESAC II and AGACC contracts), to the PRODEX Office, and to the EU SCOUT-O3, GEOmon and HYMN projects. The former two are also supported by the Belgian Federal Science Policy.

Edited by: A. Richter

\section{References}

Anderson, G. P., Chetwynd, J. H., Clough, S. A., Kneizys, F. X., and Shettle, E. P.: AFGL atmospheric constituent profiles (0120 km), Env. Res. Papers, AFGL-TR-86-0110, 1986.

Baray, J. L., Leveau, J., Baldy, S., Jouzel, J., Keckhut, P., Bergametti, G., Ancellet, G., Bencherif, H., Cadet, B., Carleer, M., David, C., De Mazière, M., Faduilhe, D., Beekmann, S. G., Goloub, P., Goutail, F., Metzger, J. M., Morel, B., Pommereau, J. P., Porteneuve, J., Portafaix, T., Posny, F., Robert, L., and Van Roozendael, M.: An instrumented station for the survey of ozone and climate change in the southern tropics: Scientific motivation, technical description and future plans, J. Environ. Monit., 8, 10, 1020-8, doi:10.1039/b607762e, 2006.

Barret, B., De Mazière, M., and Demoulin, P.: Retrieval and characterisation of ozone profiles from solar infrared spectra at the Jungfraujoch, J. Geophys. Res., 107, D24, 4788, doi:10.1029/2001JD001298, 2002.

Barret, B., De Mazière, M., and Mahieu, E.: Ground-based FTIR measurements of $\mathrm{CO}$ from the Jungfraujoch: characterisation and comparison with in-situ surface and MOPITT data, Atmos. Chem. Phys., 3, 2217-2223, 2003,

http://www.atmos-chem-phys.net/3/2217/2003/.

Bernath, P. F., McElroy, C. T., Abrams, M. C., et al.: Atmospheric Chemistry Experiment (ACE): Mission overview, Geophys. Res. Lett., 32, L15S01, doi:10.1029/2005GL022386, 2005.

Boone, C. D., Nassar, R., Walker, K. A., Rochon, Y., McLeod, S. D., Rinsland, C. P., and Bernath, P. F.: Retrievals for the atmospheric chemistry experiment Fourier-transform spectrometer, Appl. Optics, 44, 33, 7218-7231, 2005.

Brasseur, G. and Solomon, S.: Aeronomy of the Middle Atmosphere: Chemistry and Physics of the Stratosphere and Mesosphere, D. Reidel Publishing Company, 1984.

Brown, L. R., Farmer, C. B., Rinsland, C. P., and Zander, R.: Remote Sensing of the Atmosphere by High Resolution Infrared Absorption Spectroscopy, in: Spectroscopy of the Earth's Atmosphere and Interstellar Medium, edited by: Rao, K. N. and Weber, A., Academic Press, 1992.

Connor, B. J., Boesch, H., Toon, G., Sen, B., Miller, C., and Crisp, D.: Orbiting Carbon Observatory: Inverse method and prospective error analysis, J. Geophys. Res., 113, D05305, doi:10.1029/2006JD008336, 2008.

Cronn, D. and Robinson, E.: Tropospheric and Lower Stratospheric Vertical Profiles of Ethane and Acetylene, Geophys. Res. Lett., 6, 8, 641-644, 1979.

De Mazière, M., Barret, B., Vigouroux, C., Blumenstock, T., Hase, F., Kramer, I., Camy-Peyret, C., Chelin, P., Gardiner, T., Coleman, M., Woods, P., Ellingsen, K., Gauss, M., Isaksen, I., Mahieu, E., Demoulin, P., Duchatelet, P., Mellqvist, J., Strandberg, A., Velazco, V., Schulz, A., Notholt, J., Sussmann, R., Stremme, W., and Rockmann, A.: Ground-based FTIR measurements of $\mathrm{O}_{3}$ - and climate-related gases in the free troposphere and lower stratosphere, Proceedings of the Quadrennial Ozone Symposium QOS 2004 (Kos, Greece, June 1-8, 2004), P211, 2004.

Emmons, L. K., Deeter, M. N., Gille, J. C., Edwards, D. P., Attié, J.-L., Warner, J., Ziskin, D., Francis, G., Khattatov, B., Yudin, V., Lamarque, J.-F., Ho, S.P., Mao, D., Chen, J. S., Drummond, J., Novelli, P., Sachse, G., Coffey, M. T., Hannigan, J. W., Gerbig, C., Kawakami, S., Kondo, Y., Takegawa, 
N., Schlager, H., Baehr, J., and Ziereis, H.: Validation of Measurements of Pollution in the Troposphere (MOPITT) CO retrievals with aircraft in situ profiles, J. Geophys. Res., 109, D03309, doi:10.1029/2003JD004101, 2004.

Flaud, J.-M., Brizzi, G., Carlotti, M., Perrin, A., and Ridolfi, M.: MIPAS database: Validation of $\mathrm{HNO}_{3}$ line parameters using MIPAS satellite measurements, Atmos. Chem. Phys., 6, 5037-5048, 2006, http://www.atmos-chem-phys.net/6/5037/2006/.

Giglio, L., Descloitres, J., Justice, C. O., and Kaufman, Y. J.: An enhanced contextual fire detection algorithm for MODIS, Remote Sens. Environ., 87, 2-3, 273-282, 2003.

Hase, F., Blumenstock, T., and Paton-Walsh, C.: Analysis of the instrumental lineshape of high-resolution Fourier transform IR spectrometers with gas cell measurements and new retrieval software, Appl. Optics, 38, 15, 3417-3422, 1999.

Hase, F., Hannigan, J. W., Coffey, M. T., Goldman, A., Höpfner, M., Jones, N. B., Rinsland, C. P., and Wood, S. W.: Intercomparison of retrieval codes used for the analysis of high-resolution groundbased FTIR measurements, J. Quant. Spectrosc. Ra., 87, 25-52, 2004.

Hawat, T., Stephen, T. M., De Mazière, M., and Neefs, E.: Proceedings SPIE, Acquisition, Tracking and Pointing XVII, edited by: M. K. Masten, L. A. Stockum, 5082, 13-20, 2003.

Hyer, E. J., Allen, D. J., and Kasischke, E. S.: Examining injection properties of boreal forest fires using surface and satellite measurements of CO transport, J. Geophys. Res., 112, D18307, doi:10.1029/2006JD008232, 2007.

Jiang, X., Ku, W. L., Shia, R.-L., Li, Q., Elkins, J. W., Prinn, R. G., and Yung, Y. L.: Seasonal cycle of $\mathrm{N}_{2} \mathrm{O}$ : Analysis of data, Global Biogeochem. Cyc., 21, GB1006, doi: 10.1029/2006GB002691, 2007.

Meier, A., Toon, G. C., Rinsland, C. P., Goldman, A., and Hase, F.: Spectroscopic atlas of atmospheric micro-windows in the middle infrared, 2nd edition, IRF Technical Report 048, IRF Institute for Rymdfysik, Kiruna, 2004.

Neefs, E., De Mazière, M., Scolas, F., Hermans, C., and Hawat, T.: BARCOS, an automation and remote control system for atmospheric observations with a Bruker interferometer, Review of Scientific Instruments, 78, 3, 035109, doi:10.1063/1.2437144, 2007.

Notholt, J., Toon, G. C., Rinsland, C. P., Pougatchev, N. S., Jones, N. B., Connor, B. J., Weller, R., Gautrois, M., and Schrems, O.: Latitudinal variations of trace gas concentrations in the free troposphere measured by solar absorption spectroscopy during a ship cruise, J. Geophys. Res., 105, D1, 1337-1349, 2000.

Oelhaf, H., Blumenstock, T., De Mazière, M., Mikuteit, S., Vigouroux, C., Wood, S., Bianchini, G., Baumann, R., Blom, C., Cortesi, U., Liu, G. Y., Schlager, H., Camy-Peyret, C., Catoire, V., Pirre, M., Strong, K., and Wetzel, G.: Validation of MIPASENVISAT version $4.61 \mathrm{HNO}_{3}$ operational data by stratospheric balloon, aircraft and ground-based measurements, Proceedings of ACVE-2, ESA-ESRIN, Italy, 2004.

Park, J. H., Russel, J. M., III, Gordley, L. L., Drayson, S. R., Benner, D. C., McInerney, J. M., Gunson, M. R., Toon, G. C., Sen, B., Blavier, J.-F., Webster, C. R., Zipf, E. C., Erdman, P., Schmidt, U., and Schiller, C.: Validation of Halogen Occultation Experiment $\mathrm{CH}_{4}$ measurements from the UARS, J. Geophys. Res., 101, D6, 10 183-10 204, doi:10.1029/95JD02736, 1996.

Perrin, A., Orphal, J., Flaud, J.-M., Klee, S., Mellau, G., Mäder, H.,
Walbrodt, D., and Winnewisser, M.: New analysis of the $\mathrm{v}_{5}$ and $2 \mathrm{v}_{9}$ bands of $\mathrm{HNO}_{3}$ by infrared and millimeter wave techniques: line positions and intensities, J. Mol. Spectrosc., 228, 375-391, 2004.

Petersen, A.K., Warneke, T., Lawrence, M. G., Notholt, J., and Schrems, O.: First ground-based FTIR observations of the seasonal variation of carbon monoxide in the tropics, Geophys. Res. Lett., 35, L03813, doi:10.1029/2007GL031393, 2008.

Randriambelo, T., Baray, J. L., and Baldy, S.: Effect of biomass burning, convective venting, and transport on tropospheric ozone over the Indian Ocean: Reunion Island field observations, J. Geophys. Res., 105, D9, 11 813-11 832, 2000.

Reisinger, A. R., Jones, N. B., Matthews, W. A., and Rinsland, C. P.: Southern hemisphere ground based measurements of Carbonyl Fluoride $\left(\mathrm{COF}_{2}\right)$ and Hydrogen Fluoride (HF): Partitioning between flouride reservoir species, Geophys. Res. Lett., 21, 9, 797800, doi:10.1029/94GL00693, 1994.

Rinsland, C. P., Nicholas, B. J., Connor, B. J., Logan, J. A., Pougatchev, N. S., Goldman, A., Murcray, F. J., Stephen, T. M., Pine, A. S., Zander, R., Mahieu, E., and Demoulin, P.: Northern and southern hemisphere ground-based infrared spectroscopic measurements of tropospheric carbon monoxide and ethane, J. Geophys. Res., 103, D21, 28 197-28218, doi:10.1029/98JD02515, 1998.

Rinsland, C. P., Mahieu, E., Zander, R., Jones, N. B., Chipperfield, M. P., Goldman, A., Anderson, J., Russel, J. M., III, Demoulin, P., Notholt, J., Toon, G. C., Blavier, J.-F., Sen, B., Sussmann, R., Wood, S. W., Meier, A., Griffith, D. W. T., Chiou, L. S., Murcray, F. J., Stephen, T. M., Hase, F., Mikuteit, S., Schultz, A., and Blumenstock, T.: Long-term trends of organic chlorine from ground-based infrared solar spectra: Past increases and evidence for stabilization, J. Geophys. Res., 108, D8, 4252, doi:10.1029/2002JD003001, 2003.

Rodgers, C. D.: Inverse Methods for Atmospheric Sounding: Theory and Practice, Series on Atmospheric, Oceanic and Planetary Physics, Vol. 2, World Scientific, Singapore, 2000.

Rodgers, C. D. and Connor, B. J.: Intercomparison of remote sounding instruments, J. Geophys. Res., 108, D3, 4116, doi:10.1029/2002JD002299, 2003.

Rothman, L. S. Jacquemart, D., Barbe, A., Benner, D. C., Birk, M., Brown, L. R., Carleer, M. R. Chackerian, Jr. C., Chance, K., Coudert, L. H., Dana, V., Devi, V. M., Flaud, J. M., Gamache, R.,R., Goldman, A., Hartmann, J.,M., Jucks, K.,W., Maki, A.,G., Mandin, J.,Y., Massie, S.,T., Orphal, J., Perrin, A., Rinsland, C. P., Smith, M. A. H., Tennyson, J., Tolchenov, R. N., Toth, R. A., Vander, J., Varanasi, P., and Wagner, G.: The Hitran 2004 molecular spectroscopic database, J. Quant. Spectrosc. Ra., 96, 139-204, 2005.

Rudolph, J. and Ehhalt, D. H.: Measurements of C2-C5 hydrocarbons over the North Atlantic, J. Geophys. Res., 86, C12, $11959-$ $11964,1981$.

Russell, J. M., III, Deaver, L. E., Luo, M., Park, J. H., Gordley, L. L., Tuck, A. F., Toon, G. C., Gunson, M. R., Traub, W. A., Johnson, D. G., Jucks, K. W., Murcray, D. G., Zander, R., Nolt, I. G., and Webster, C. R.: Validation of hydrogen chloride measurements made by the Halogen Occultation Experiment from the UARS platform, J. Geophys. Res., 101, D6, 10 151-10 162, doi:10.1029/95JD01696, 1996a.

Russell, J. M., III, Deaver, L. E., Luo, M., Cicerone, R. J., Park, J. 
H., Gordley, L. L., Toon, G. C., Gunson, M. R., Traub, W. A., Johnson, D. G., Jucks, K. W., Zander, R., and Nolt, I. G.: Validation of hydrogen fluoride measurements made by the Halogen Occultation Experiment from the UARS platform, J. Geophys. Res., 101, D6, 10 163-10 174, doi:10.1029/95JD01705, 1996 b.

Schneider, M., Blumenstock, T., Chipperfield, M. P., Hase, F., Kouker, W., Reddmann, T., Ruhnke, R., Cuevas, E., and Fischer, H.: Subtropical trace gas profiles determined by ground-based FTIR spectroscopy at Izaña $\left(28^{\circ} \mathrm{N}, 16^{\circ} \mathrm{W}\right)$ : Five-year record, error analysis, and comparison with 3-D CTMs, Atmos. Chem. Phys., 5, 153-167, 2005,

http://www.atmos-chem-phys.net/5/153/2005/.

Smit, H. G. J. and Straeter, W.: JOSIE-2000, Jülich Ozone Sonde Intercomparison Experiment 2000, The 2000 WMO international intercomparison of operating procedures for ECC-ozone sondes at the environmental simulation facility at Jülich, WMO Global Atmosphere Watch report series, No. 158, World Meteorological Organization, Geneva, 2004.

Smith, M. A. H.: Compilation of atmospheric gas concentration profiles from 0 to $50 \mathrm{~km}$, NASA TM 83289, 1982.

Stohl, A., Hittenberger, M., and Wotawa, G.: Validation of the Lagrangian particle dispersion model FLEXPART against large scale tracer experiment data, Atmos. Environ., 24, 4245-4264, 1998.

Stohl, A., Forster, C., Frank, A., Seibert, P., and Wotawa, G.: Technical Note: The Lagrangian particle dispersion model FLEXPART version 6.2., Atmos. Chem. Phys., 5, 2461-2474, 2005, http://www.atmos-chem-phys.net/5/2461/2005/.

Sussmann, R. and Borsdorff, T.: Technical Note: Interference errors in infrared remote sounding of the atmosphere, Atmos. Chem. Phys. 7, 3537-3557, 2007.

Urban, J., Lautié, N., Le Flochmoën, E., Jiménez, C., Eriksson, P., de La Noë, J., Dupuy, E., Ekström, M., El Amraoui, L., Frisk, U., Murtagh, D., Olberg, M., and Ricaud, P.: Odin/SMR limb observations of stratospheric trace gases: Level 2 processing of $\mathrm{ClO}, \mathrm{N}_{2} \mathrm{O}, \mathrm{HNO}_{3}$, and $\mathrm{O}_{3}$, J. Geophys. Res., 110, D14307, doi: 10.1029/2004JD005741, 2005.
U.S. National Oceanic and Atmospheric Administration: U.S. Standard Atmosphere: 1976 published by the U.S. Government Printing Office, Washington, D.C., 1976.

Van der Werf, G. R., Randerson, J. T., Giglio, L., Collatz, G. J., and Kasibhatla, P. S.: Interannual variability in global biomass burning emission from 1997 to 2004, Atmos. Chem. Phys., 6, 34233441, 2006, http://www.atmos-chem-phys.net/6/3423/2006/.

Wang, D. Y., Höpfner, M., Blom, C. E., Ward, W. E., Fischer, H., Blumenstock, T., Hase, F., Keim, C., Liu, G. Y., Mikuteit, S., Oelhaf, H., Wetzel, G., Cortesi, U., Mencaraglia, F., Bianchini, G., Redaelli, G., Pirre, M., Catoire, V., Huret, N., Vigouroux, C., De Mazière, M., Mahieu, E., Demoulin, P., Wood, S., Smale, D., Jones, N., Nakajima, H., Sugita, T., Urban, J., Murtagh, D., Boone, C. D., Bernath, P. F., Walker, K. A., Kuttippurath, J., Kleinböhl, A., Toon, G., and Piccolo, C.: Validation of MIPAS $\mathrm{HNO}_{3}$ operational data, Atmos. Chem. Phys., 7, 4905-4934, 2007, http://www.atmos-chem-phys.net/7/4905/2007/.

WMO WDCGG Data Summary. WDCGG No. 30, GAW Data, Volume IV Greenhouse Gases and Other Atmospheric Gases, published by Japan Meteorological Agency, in co-Operation with the World Meteorological Organization, March 2006.

Zander, R., Mahieu, E., Demoulin, P., Duchatelet, P., Servais, C., Roland, G., Delbouille, L., De Mazière, M., and Rinsland, C. P.: Evolution of a dozen non- $\mathrm{CO}_{2}$ greenhouse gases above Central Europe since the mid-1980s, Environ. Sci., (Special Issue: Non$\mathrm{CO}_{2}$ Greenhouse Gases), 2, 2-3, 295-303, 2005.

Zhao, Y., Strong, K., Kondo, Y., Koike, M., Matsumi, Y., Irie, H., Rinsland, C. P., Jones, N. B., Suzuki, K., Nakajima, H., Nakane, H., and Murata, I.: Spectroscopic measurements of tropospheric $\mathrm{CO}, \mathrm{C}_{2} \mathrm{H}_{6}, \mathrm{C}_{2} \mathrm{H}_{2}$, and $\mathrm{HCN}$ in northern Japan, J. Geophys. Res., 107, D18, 4343, doi:10.1029/2001JD000748, 2002. 